\title{
PATTERNS OF BRAIN THINKING BY NED HERMANN AMONG STUDENTS OF POST-BASIC EDUCATION IN THE PROVINCE OF SOUTH EASTERN OMAN
}
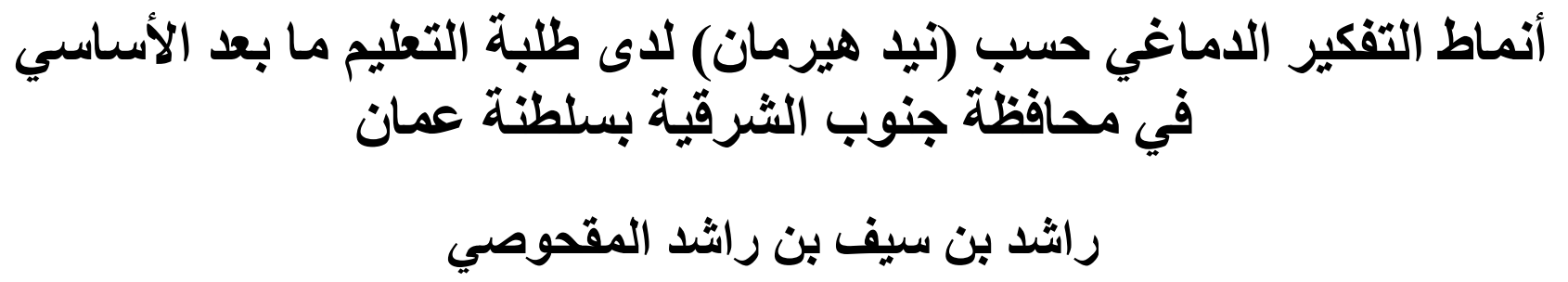

\author{
Al Maqhousi Rashid Saif Rashid ${ }^{1 *}$, Arifin Mamat ${ }^{2}$ \\ ${ }^{1}$ Ph.D. Candidate, Faculty of Education, International Islamic University Malaysia (IIUM), \\ rashid303020@gmail.com \\ ${ }^{2}$ Prof. Dr., Kulliyyah of Education, International Islamic University Malaysia (IIUM), \\ drarifin@iium.edu.my \\ *Corresponding Author
}

\begin{abstract}
This article discusses the patterns of brain thinking according to (Ned Hermann) among post-basic education students in the South Sharqiyah Governorate in the Sultanate of Oman and it is part of a field study conducted by the researcher in government schools affiliated with the Ministry of Education in the Sultanate of Oman. The research problem lies in the lack of awareness among students of post-basic education in the Governorate of South Sharqiya in the Sultanate of Oman of the importance of knowing their thinking patterns in the close relationship between him and his academic achievement, and thus choosing a major in a way that is consistent with his thinking style. And therefore his inability to complete the study normally or lose the opportunity to learn. Therefore, it constituted a very important problem that deserves study and research. Therefore, the study aimed at identifying the brainstorming patterns according to (Ned Herman) among postbasic education students in the Governorate of South Al Sharqiyah in the Sultanate of Oman, and to answer the study question, the researcher used the descriptive analytical method to identify the brainstorming patterns according to (Ned Hermann) among post-basic education students. By selecting a random sample of (654) male and female students for the academic year 2020-2021 AD, the results showed that of the students constituting (11.16\%) of the total of the actual sample, they have a secondary preference for patterns, as for the basic patterns, the degree of students' ownership of the patterns varied Between having only one pattern, and some having all four patterns(A-B-C-D), and the results indicate that the prevailing pattern among students is their possession of all four types (A-B-C-D), and what constitutes (39.3\%), and the lowest pattern is the pattern that combines (B-D) with a rate of $(0.76 \%)$. The results also showed on the level of the number of patterns that type (A) came first at the level of monotypes.
\end{abstract}

Keywords: thought patterns, Ned Hermann model, post-basic education students) 


\section{الملخص}

يناقش هذا المقال أنماط التفكير الدماغي حسب (نيد هيرمان) لانى طلبة التعليم ما بعد الأساسي في محافظة

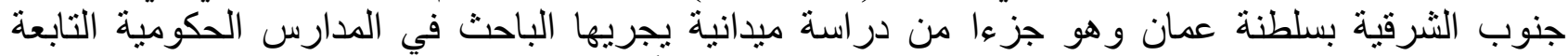

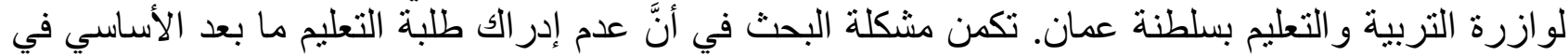

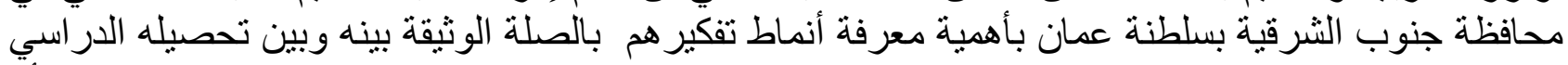

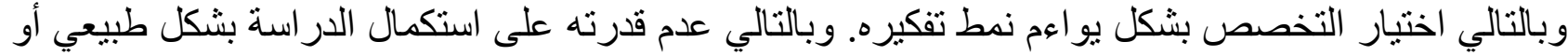

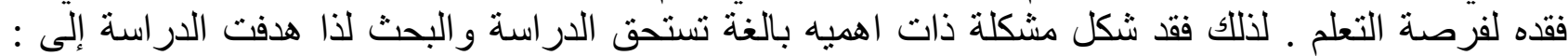

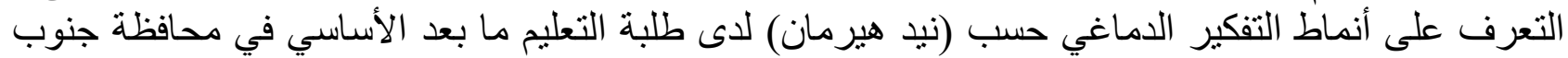

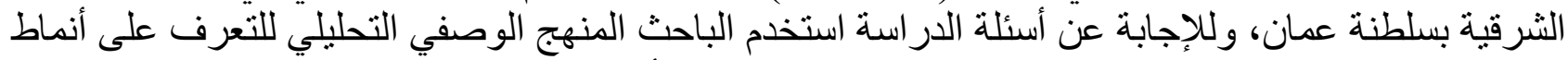
التفكير الدماغي حسب (نيد هيرمان) لاى طلبة التعليم ما بعد الأساسي. من خلال اختيار عينة عشوائية بلغت

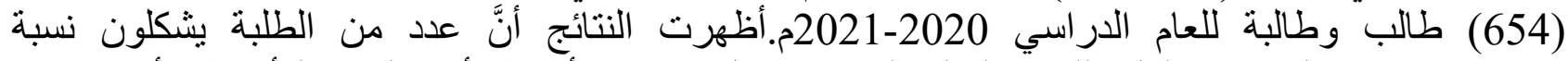
(11.16\%) من المجموع الكلي للعينة الفعلية لديهم تفضيل ثانوي الأنماط، أما بالنسبة للأنماط الأساسية فقد الأنة

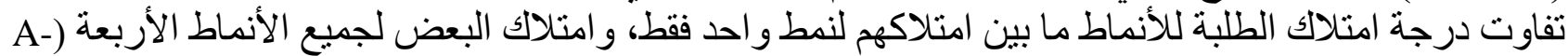

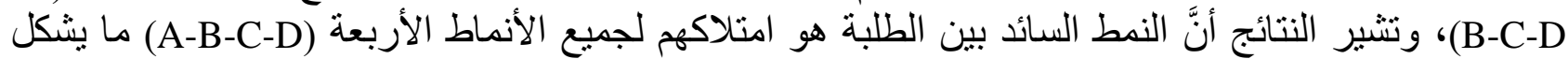

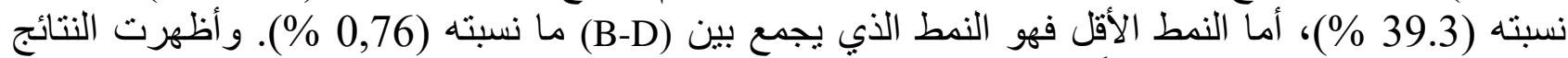
أيضا على مستوى عدد الأنماط أنَّ النمط (A) جاء في الترتيب في الأول على مستوى الأنماط الأحادية. الكلمات المفتاحية: أنماط التفكير، نموذج نبد هيرمان، طلبة بعد الأساسي.

\section{المقدمة}

تعتبر أنماط التفكير جزءًا من تقنيات إدارة الدماغ التي تساعد في معالجة المعلومات وكذلك في

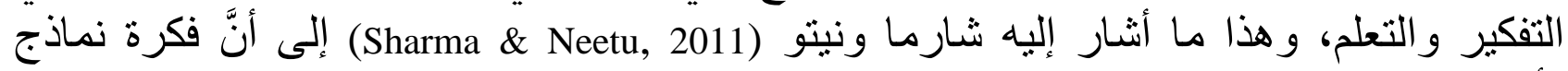
لأسلوب التحكم في الدماغ تهيمن على الإنسان، مما يسمح لله بمعالجة المعلومات المختلفة وتميزه

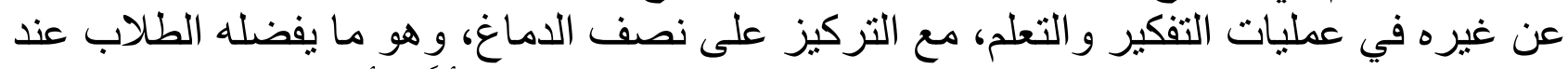

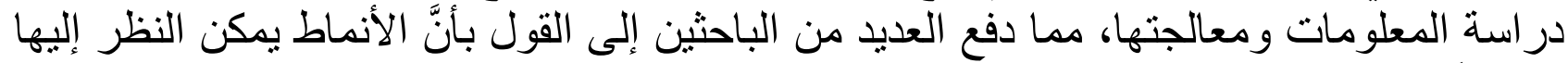
على أنَّها اتجاهات وليست قدرات وتختلف أنماط التفكير منها ما بركز على شخصية التحنية المتعلم،

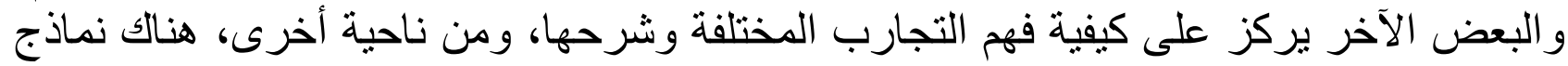
تركز على الإدر الك الحسي.(Bawaneh, Abdullah, Saleh \& Yin, 2011) .

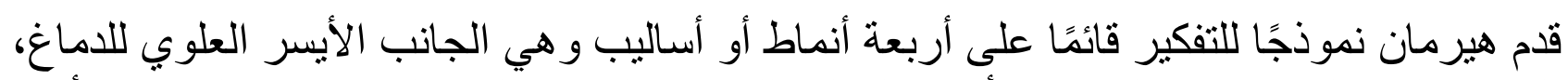

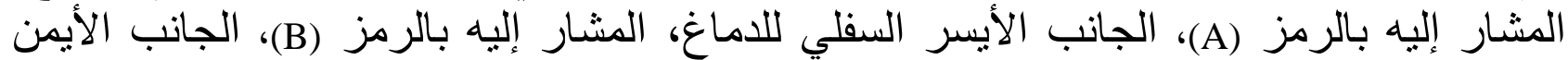
السفلي من الدماغ. الدماغ، ويشار إليها بالرمز (C)، و الجزء الجه العلوي الأيمن من الدماغ المشار إليه إليه

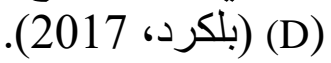

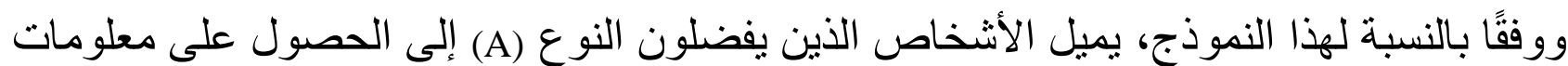

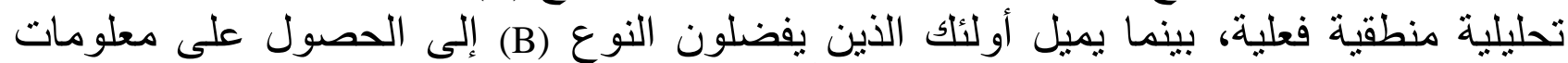

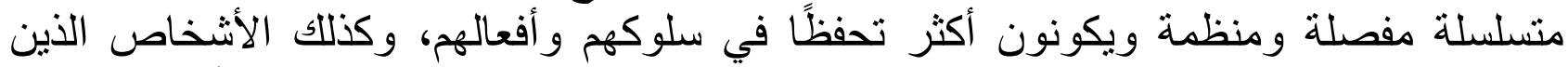

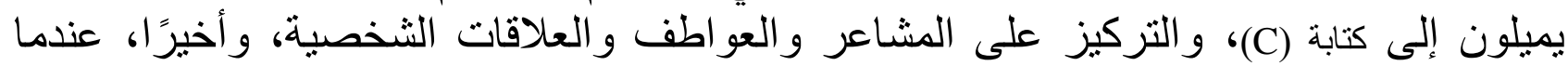
يتعلق الأمر بالأشخاص الذين يفضلون النوع (D)، فأنَّهم يميلون إلى التفكير بشكل كلي 
و مفاهيمي(Boer \& Bothma, 2003).

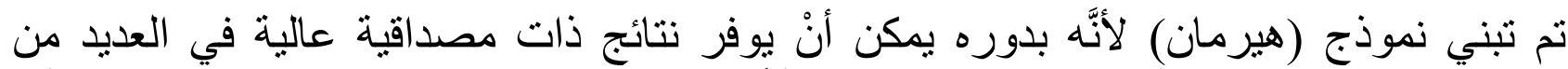

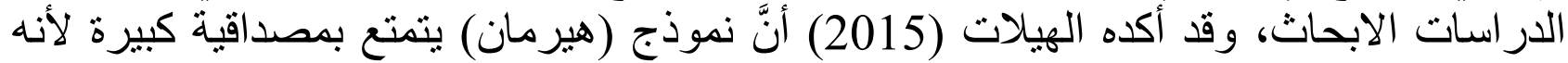
يتميز بالمعاملات مع الموثوقية والثبات، وهي عائتنه التي يستخدمها في العديد من الداراسات و الابحاث، حيث تم بناء نموذج (هيرمان) في أكثر من 15 عامًا على الأبحاث الذي في قدمها سبيري

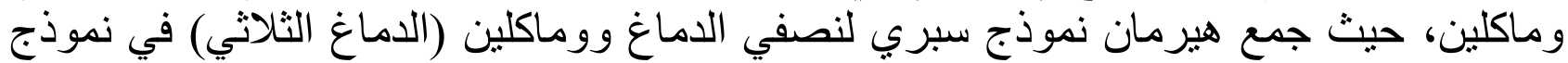
و احد، و هو (نموذج هيرمان) رباعي منذ أنْ أكدثْ أبحاث "ماكلين" وجود ثناثنة أدمغة في الإنسان بعضها فوق البعض وهو هي (الدماغ العقلي: والذي يثنمل التفكير والإدر الك و التعلم، دماغ الثدييات:

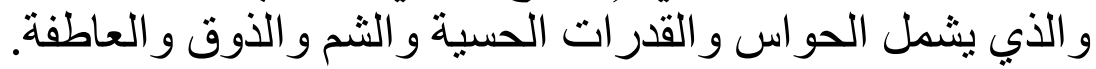

يمكن أنْ يلعب استخدام النموذج (نموذج هيرمان) كطريقة تدريس حديثة دورًا في تتمية تفكير الطلاب، حيث يتحمل المعلمون مسؤولية كبيرة مرتبطة، في المقام الأول، بالحاجة إلى استخدام طرق التدريس الحديثة، من ناحية أخرى بهدف تشجيع الطلاب على التفكير في القضايا و التعامل

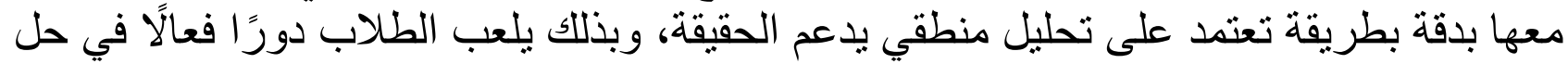
العديد من مثكلات التعلم وفي تحقيق الأهداف المرجوة (العابدي، 2014). وقد أكدت الكدي العديد من

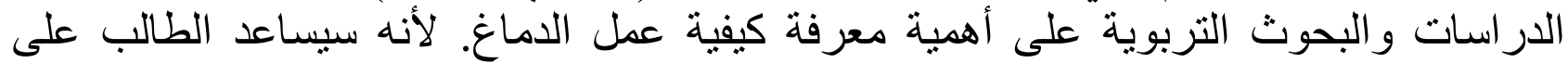
اكتساب المعرفة المختلفة ويساعد أيضًا في اختيار تخصص يتو افق مع مع نمط التفكير الذي يعتمد عليه (الهمانان، 2013). تساعد نماذج التفكير الطلاب أيضًا على معالجة المعلومات وحل المشكلات. أكد كل من بيلوسوفا

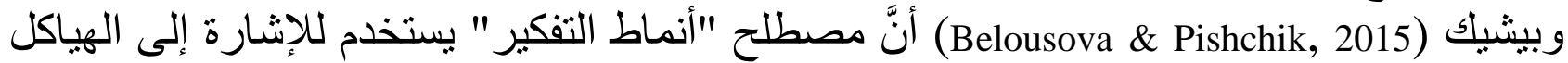
العقلية التي تسمح للشخص بمعالجة المعلومات وحل المشكلات. مشكلة الاراسة:

أصبحت أنماط التفكير موضوع نقاش واسع في العديد من السياقات التعليمية، خاصة و أنَّ فهم

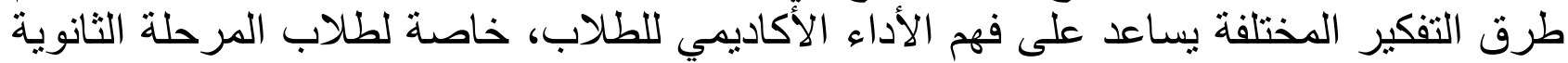

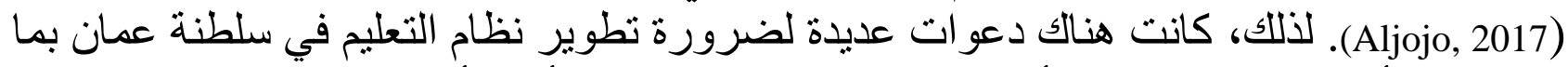
يتو افق مع أحدث الاتجاهات في أبحاث الدماغ. في هذا الصدد، أبرز أبو بكر (2010) الحاجة إلى إنى تعليم الطلاب استخدام نصفي اللدماغ الأيمن والأيسر أثناء التعلم، وكذلك الحاجة إلى تطوير منهج قائم على المفاهيم بدلاً من الحقائق المجردة، وضرورة التنويع في الاستراتيجيات التعليمية

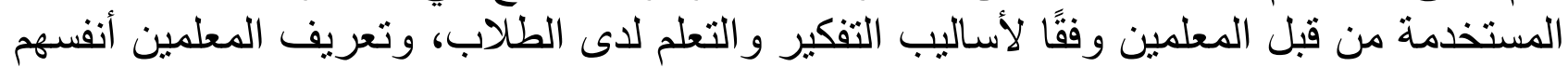

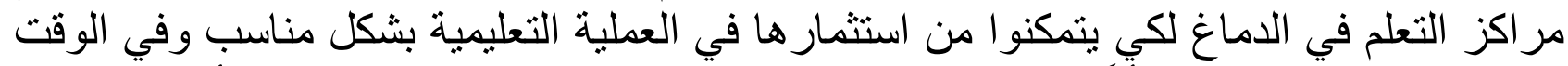

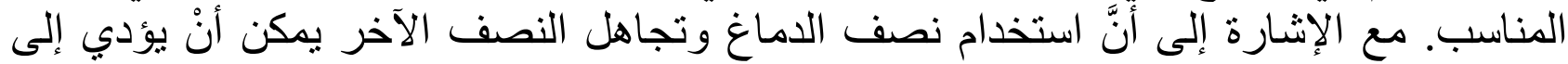

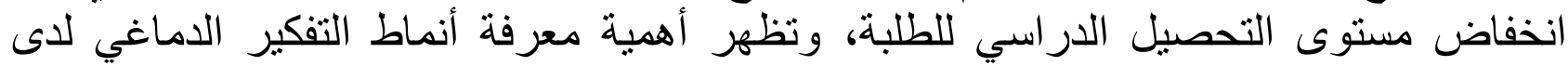
الطلبة؛ في توجيه تفكير هم نحو الاختيار الصحيح للتخصصيات و السعي لتطوير أو تطوير أنماط تفكير هم في المستقبل. هدف الار استة: تشخيص ومناقثنة أنماط التفكير الدماغي حسب نموذج (نيد هيرمان) لدى طلبة التعليم ما بعد 
الأساسي.

الإطار النظري والاراسات السابقة:

أولاً: الإطار النظري

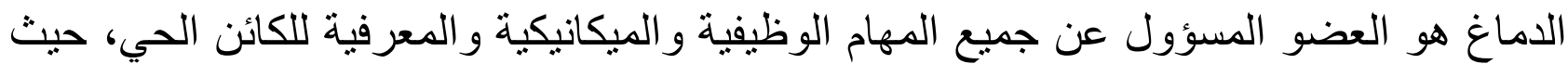

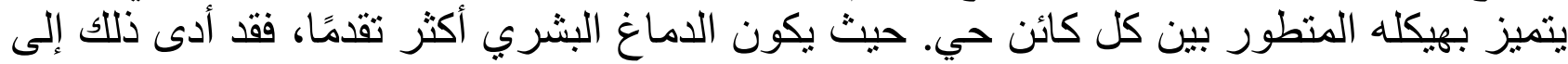

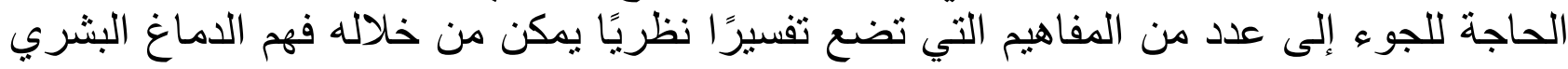

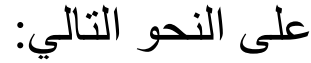

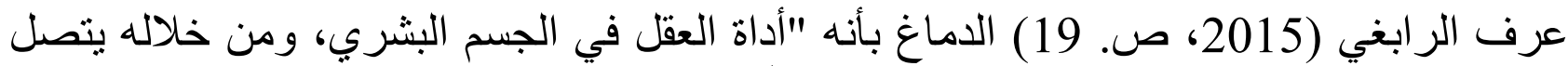

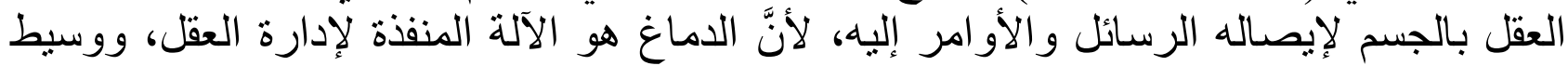

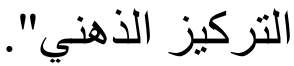

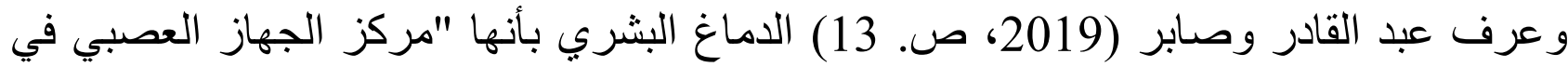

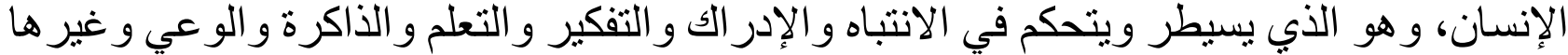

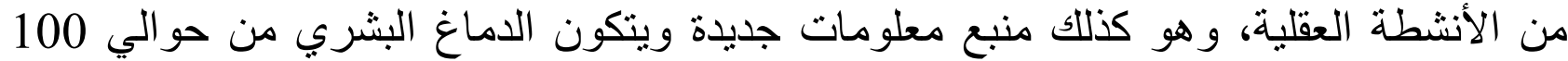

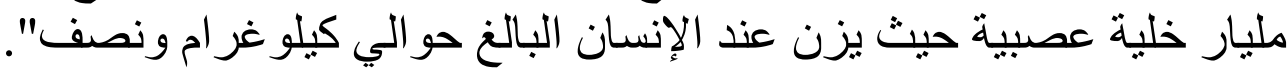
تقسيم الاماغ

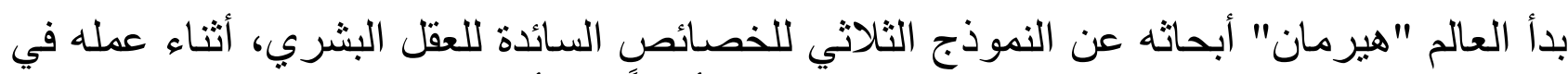

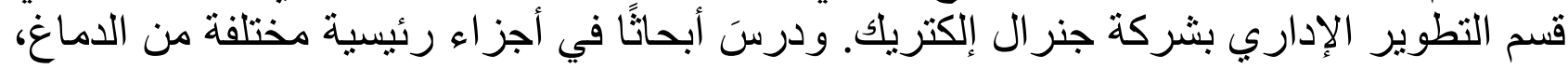

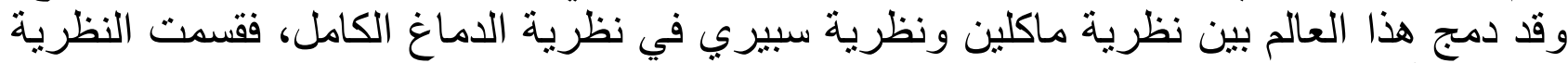
الأماغ وفقًا للخصائص التعليمية إلى دئي ماكلين - الجزء العلوي: و الذي يختص بالمفاهيمية و التجريد. - - الجزء السفلي: و الذي يختص بالعاطفة.

- - - الجزء الأيسر : و الذي يختص بالمنطقية و الكمية في أعلاه وبالتسلسلية و التنظيم في أسفله.

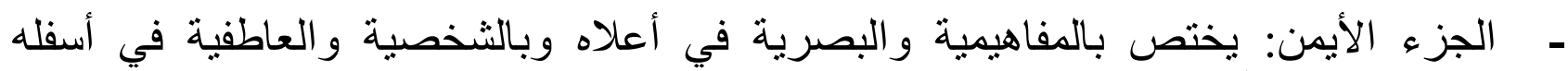

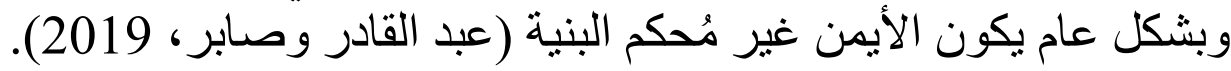

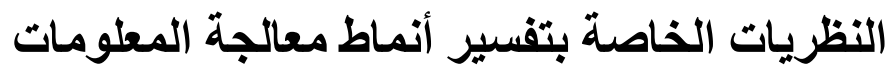

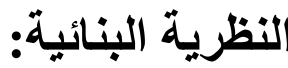

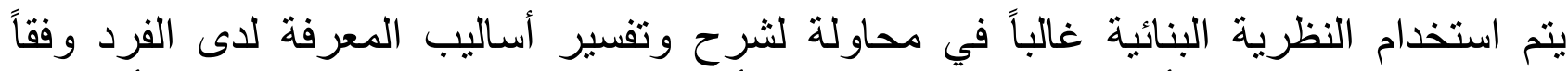

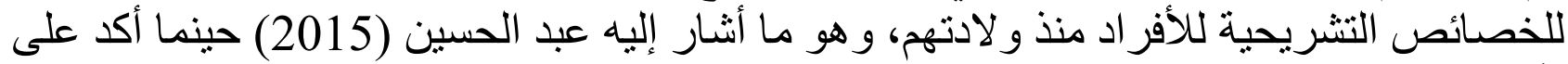

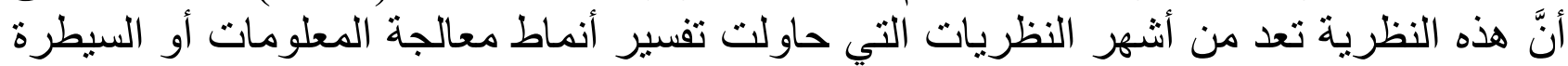

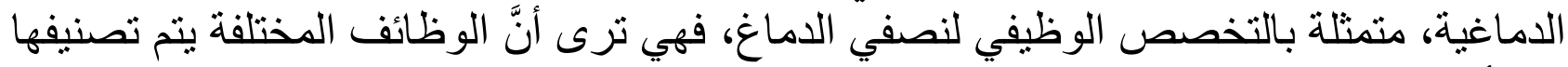

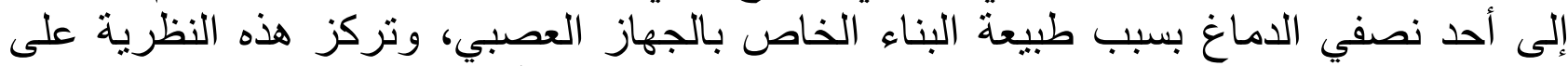

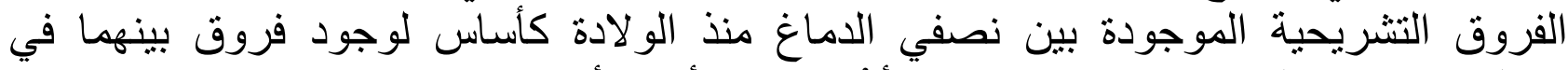

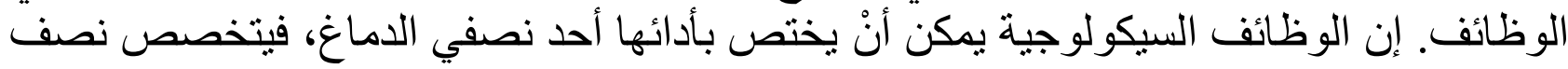


المخ الأيمن ويعمل بطريقة شمولية معتمداً على الحدس والخيال و الصور الحسية، في حين يتخصص النصف الأيسر ويعمل بطريقة منطقية استدلالية تتابعية.

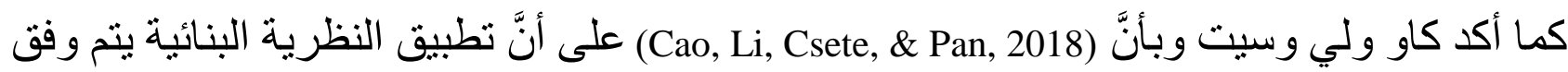

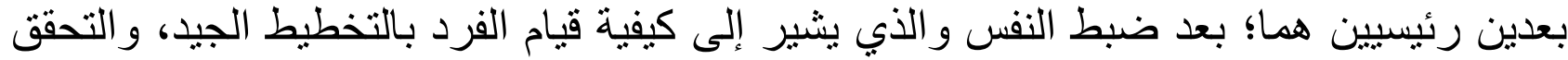

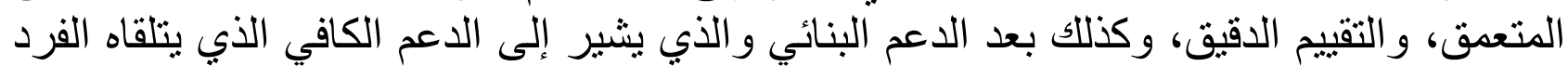

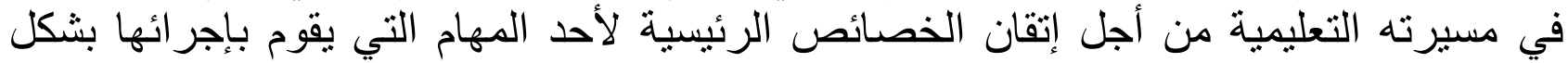

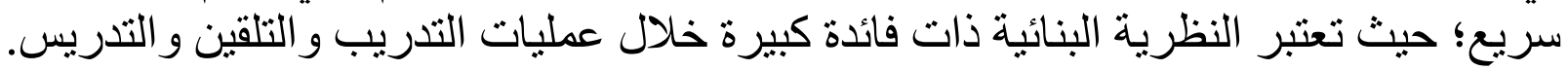

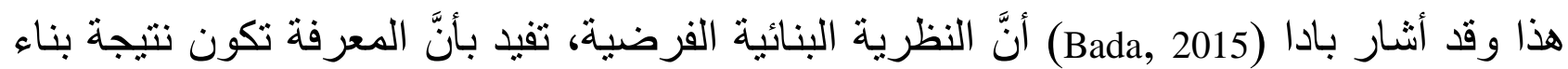

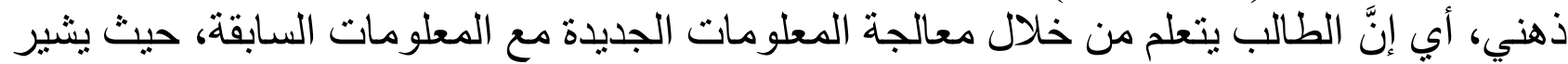

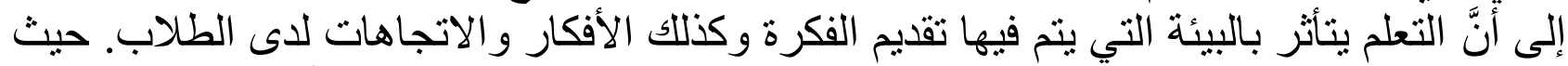

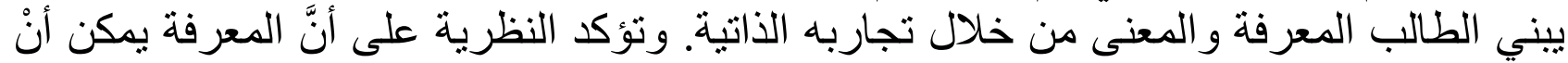

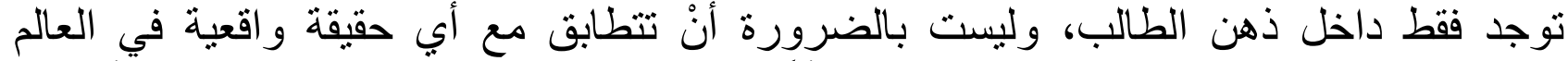

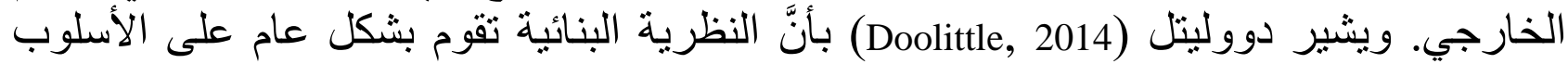
الذي ييني به الطلاب المعرفة الذاتية من تفسير تجاربهم الخاصة، حيث يشير النير إلى البنائية على أنها

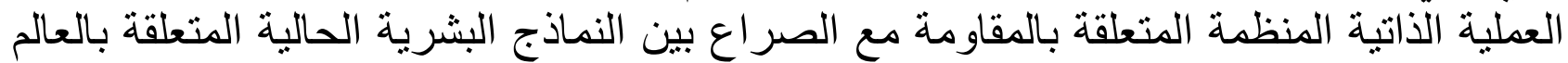
و الرؤى الجديدة المتناقضة، وبناء تمثيلات ونماذج جديدة منعلقة بالو اقع.

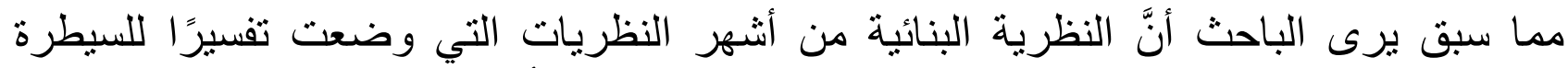

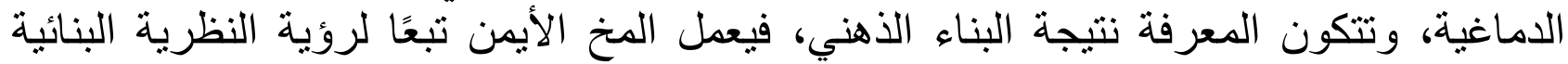

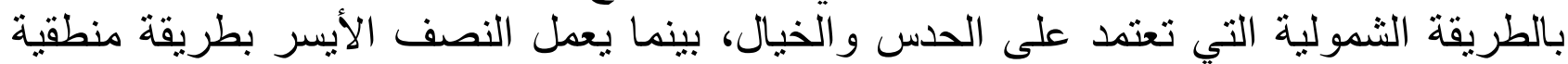

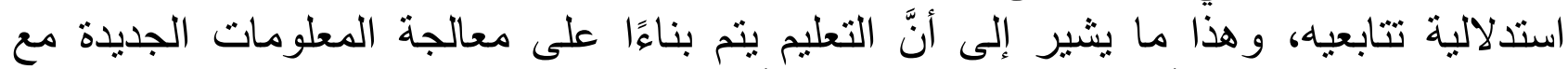

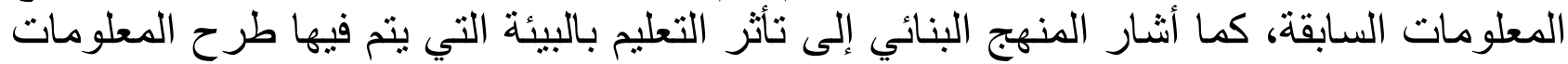

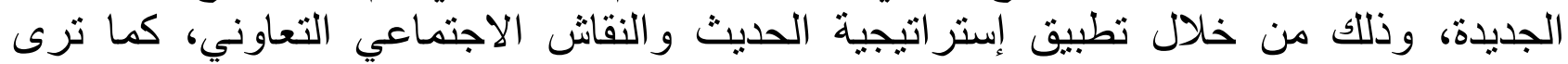

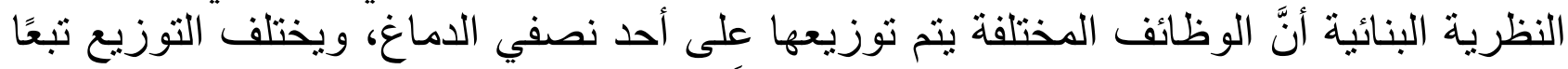

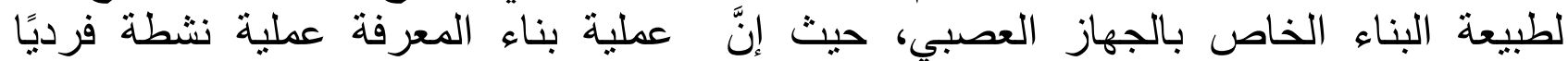

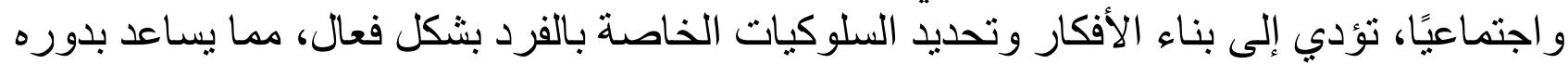

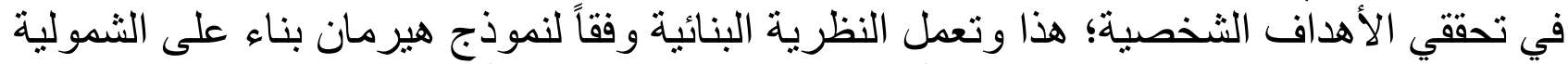

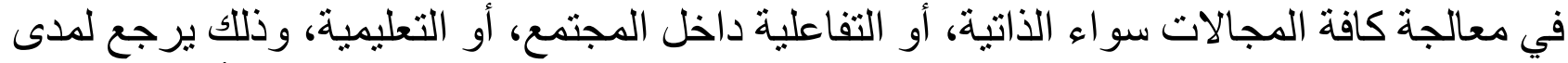

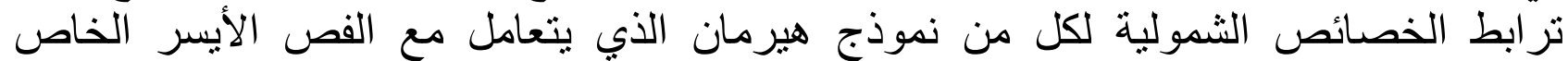

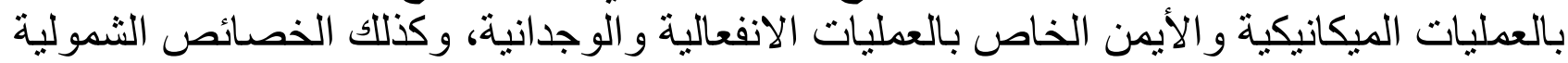

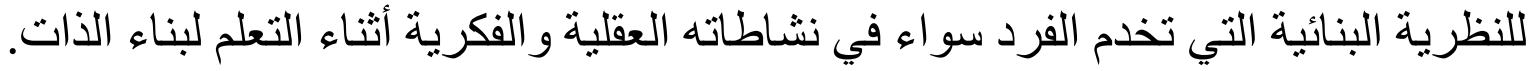

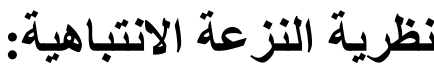

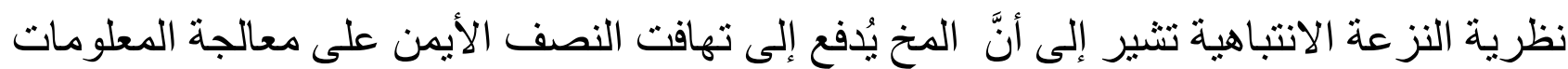

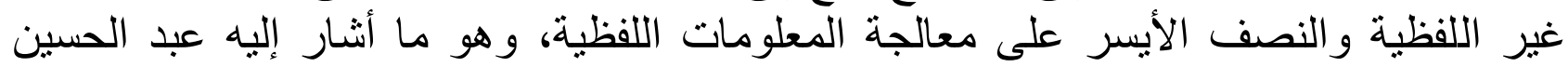

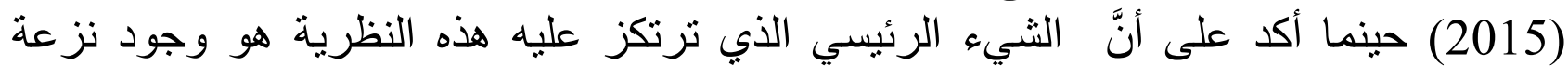

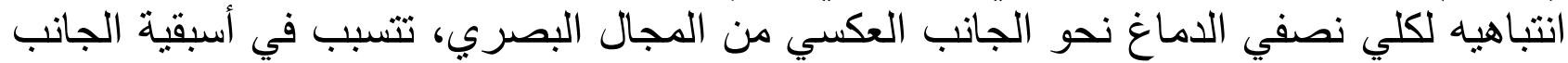

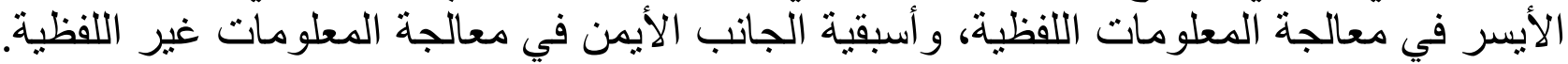




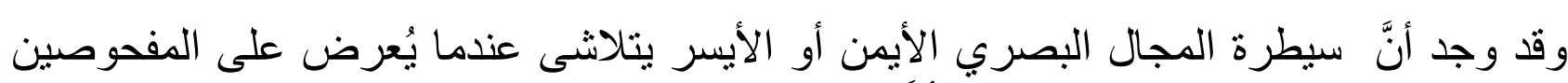

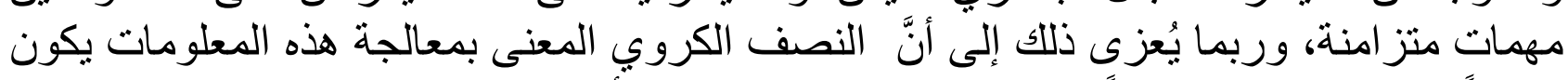

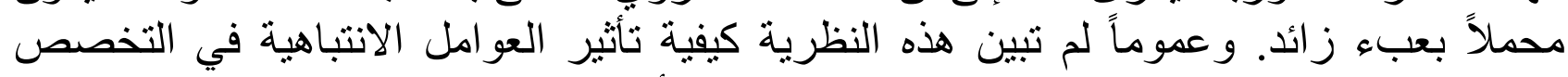

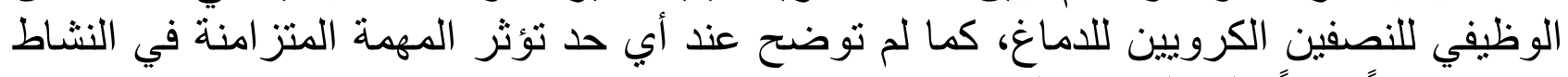

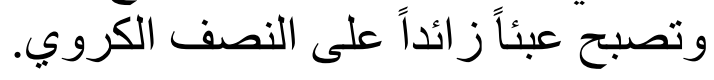

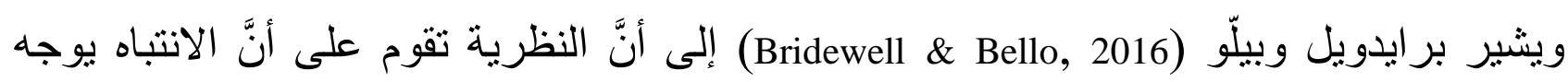

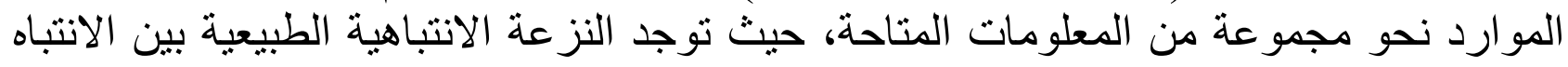

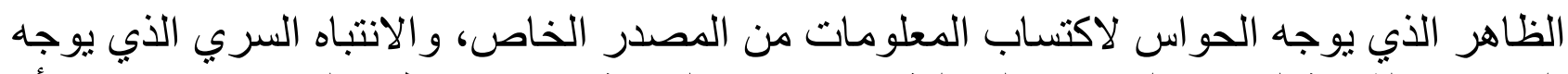

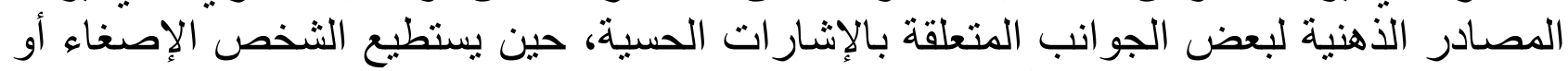

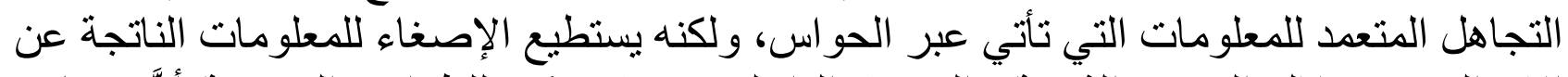

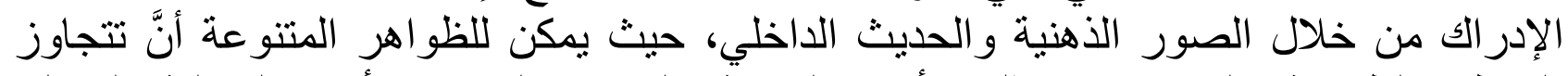

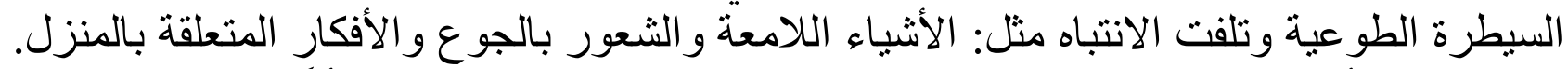

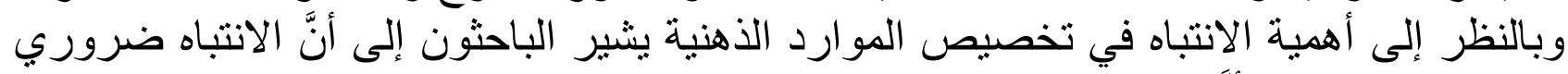

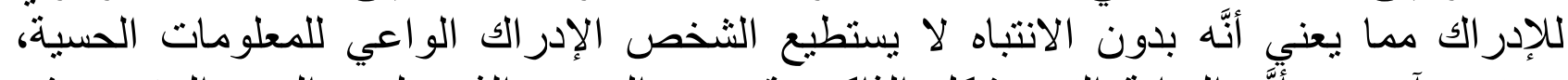

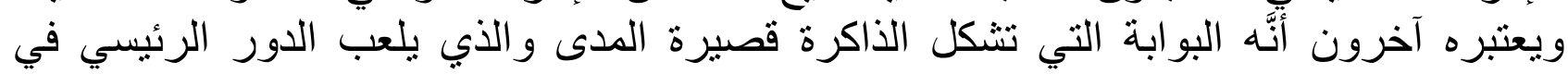

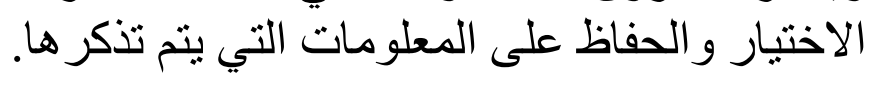
يستنتج الباحث أنَّ نظرية النزعة الانتباهية تشير إلى أسبقية الجانب الأيسر في مهارة معالجة الإنة

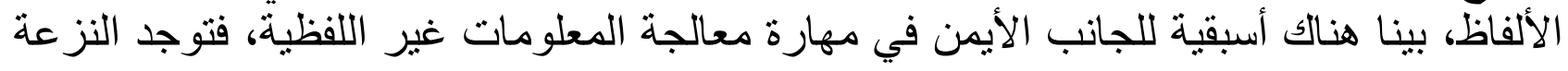

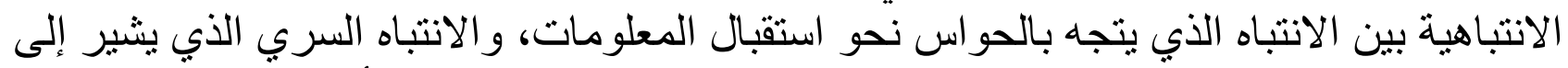

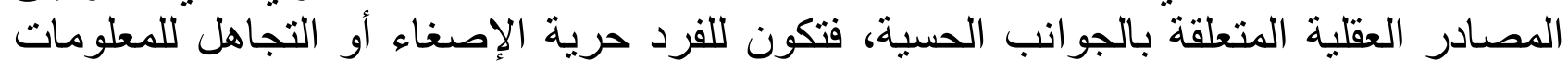

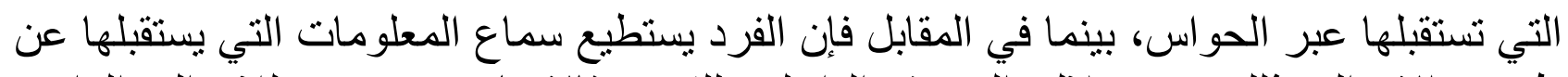

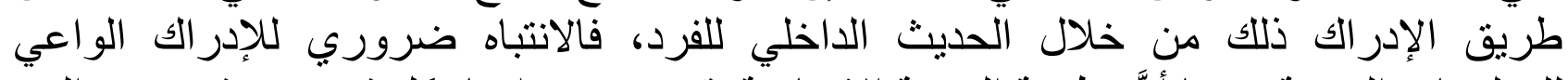

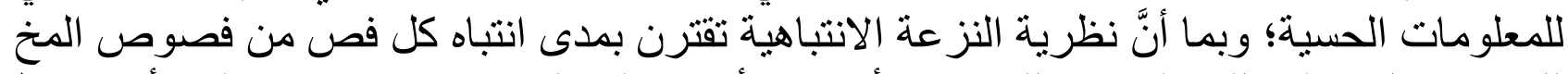

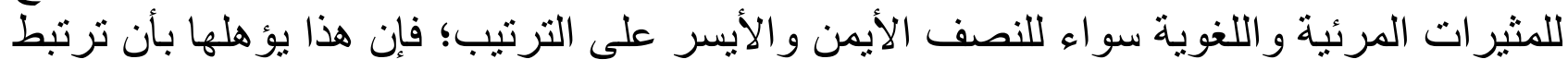

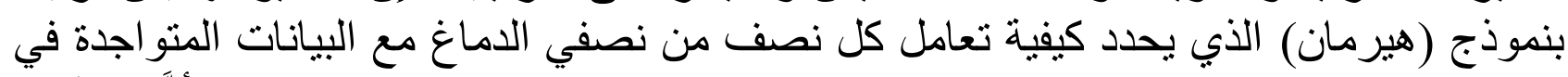

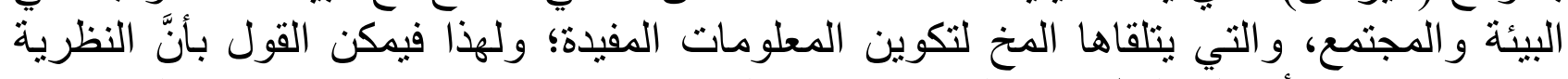

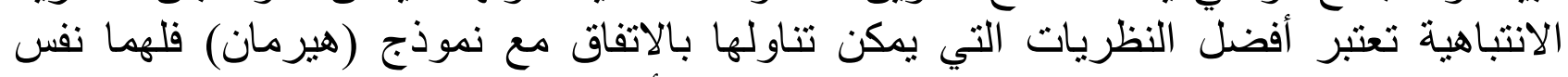

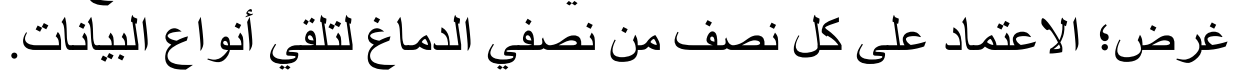

\section{النظرية التكاملية للنصفين الكرويين بالمخي:}

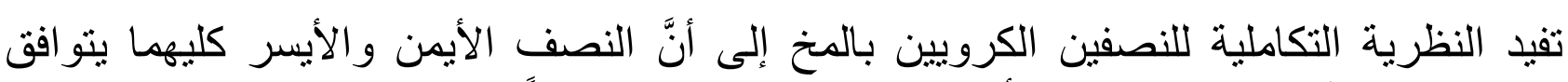

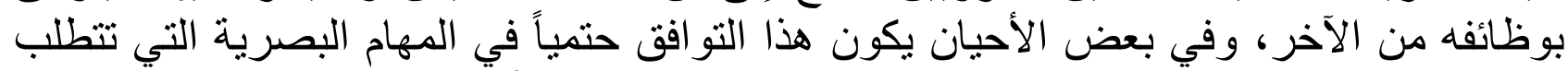

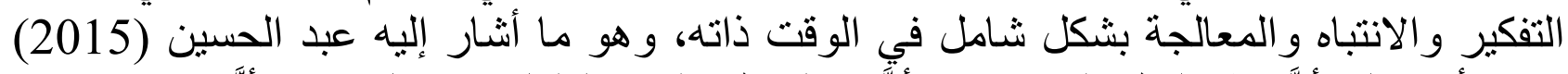

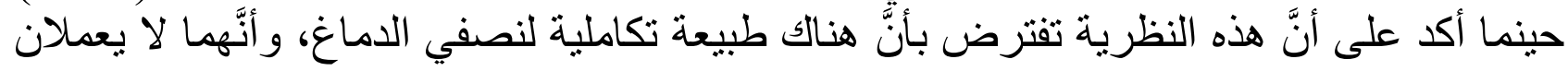

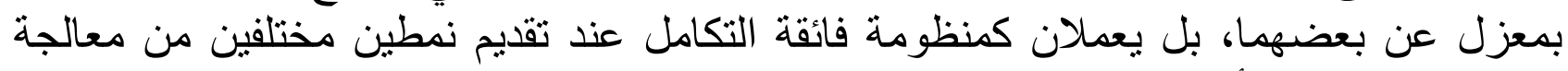

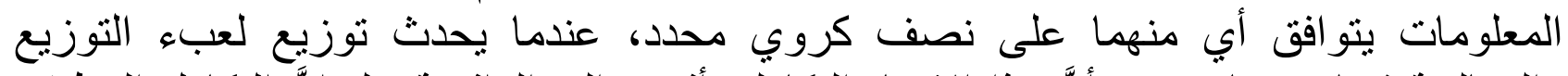

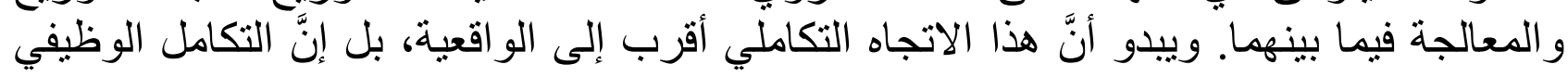




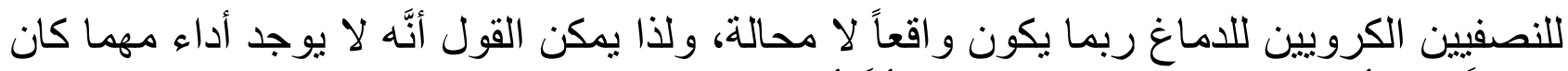

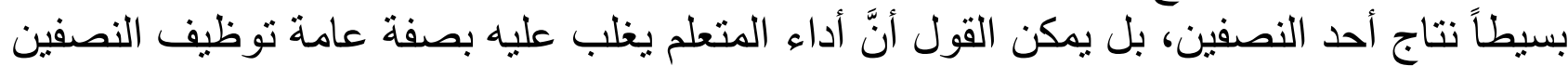

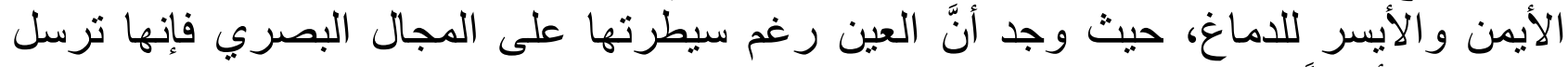

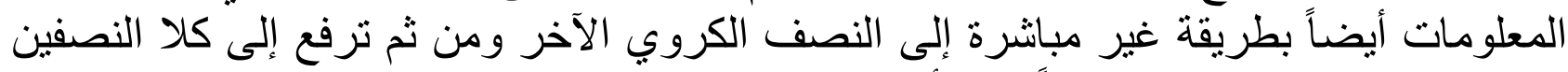
وتتم معالجتها بطريقة مختلفة تبعاً لنمط أبي منهما. النها.

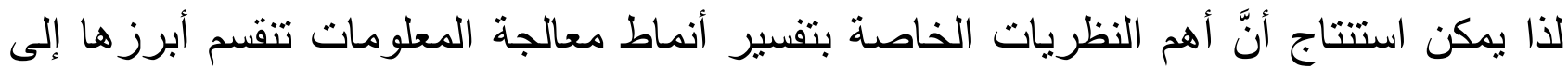

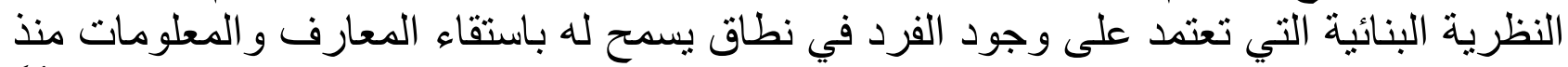

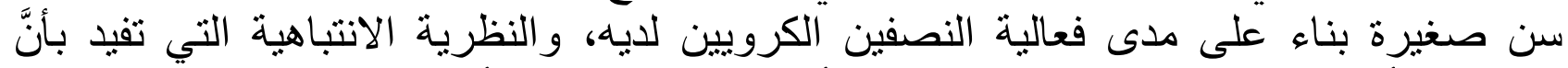

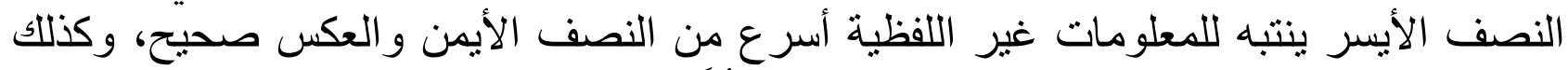

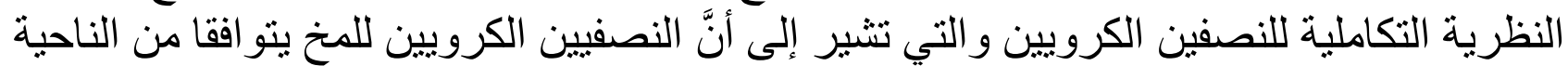

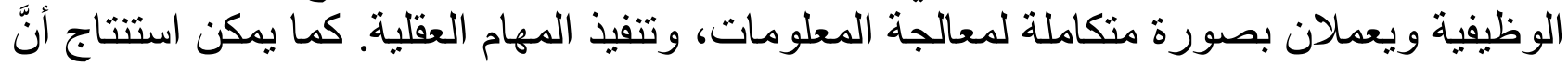

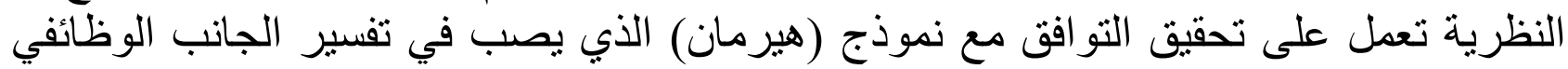

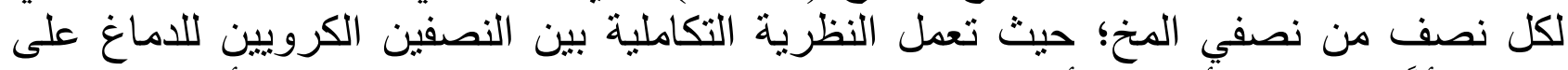

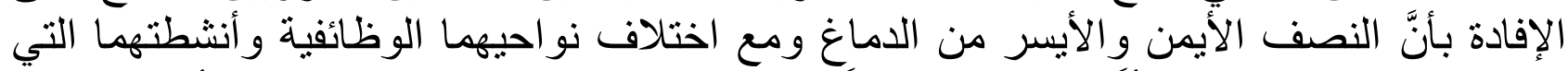

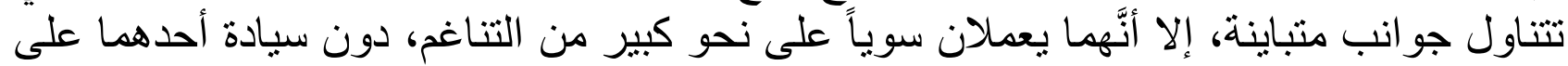

\section{تعريف السيطرة الاماغية}

لقد تعددت تعريفات مفهوم السيطرة الدماغية، حيث دارت جميع التعريفات حول النصفين

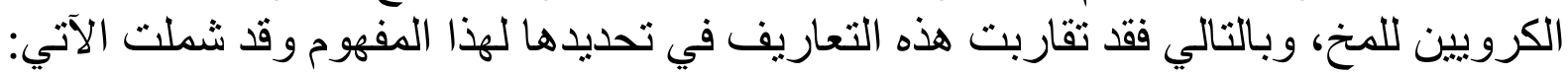

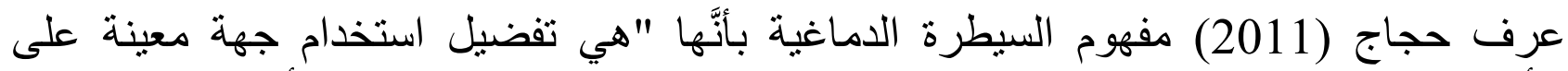

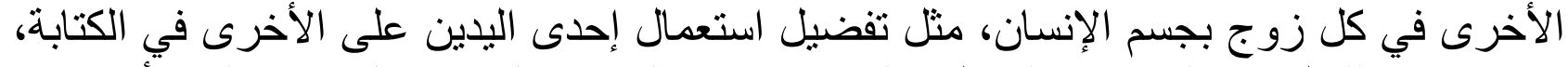

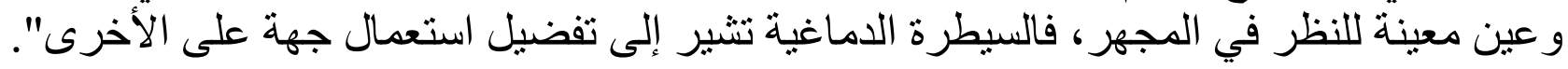

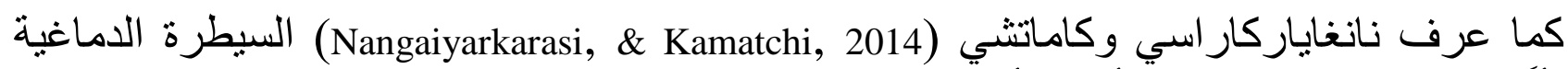

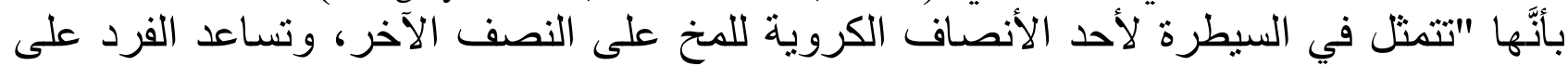

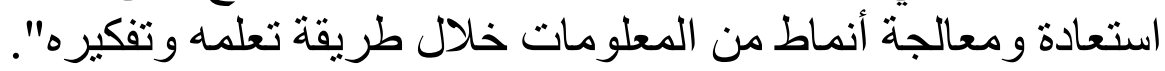

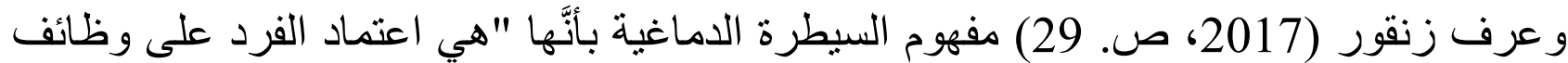

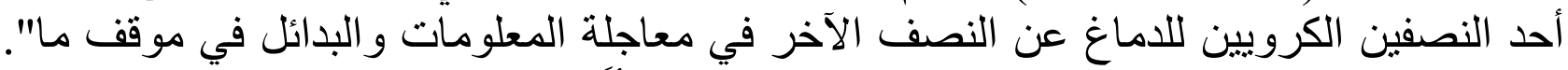

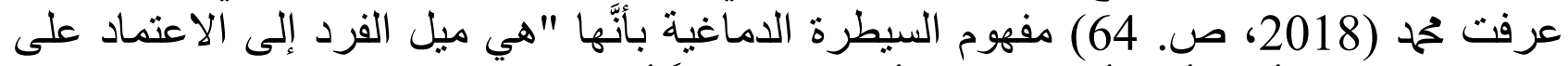

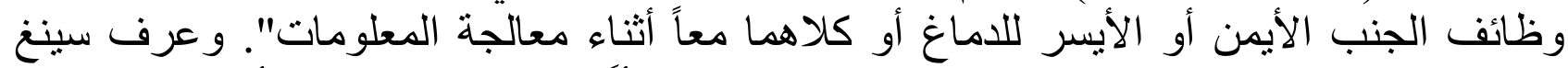

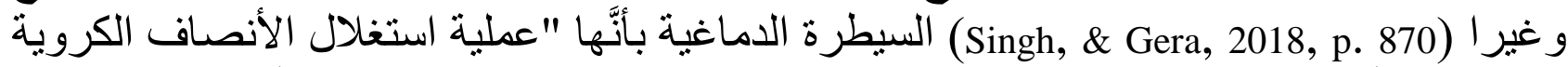

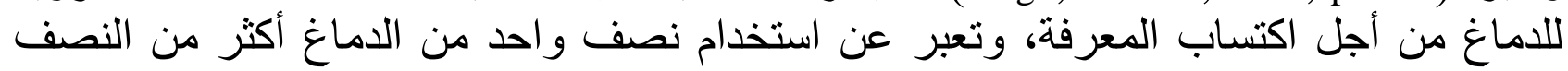
الآخر". النماذج المفسرة للسيطرة الدماغية: 


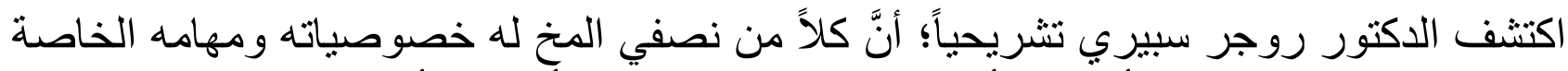

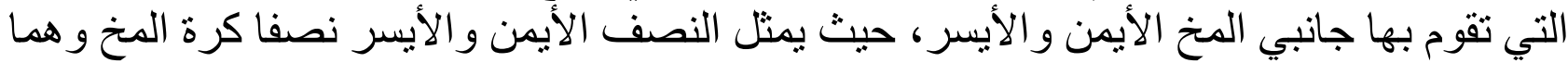

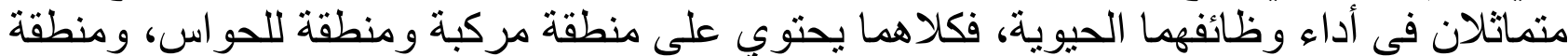

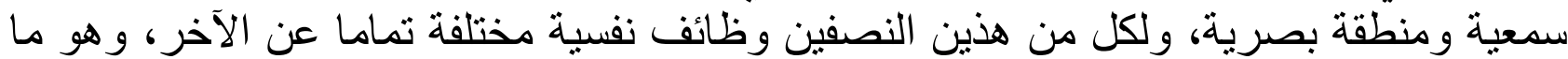

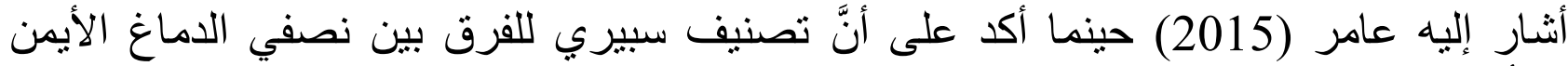

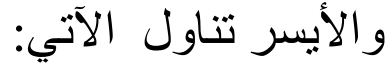

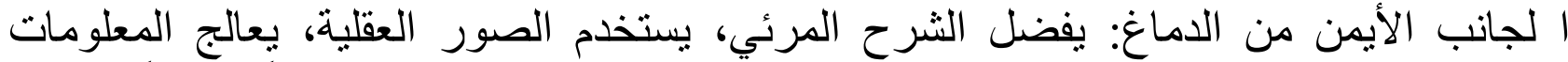

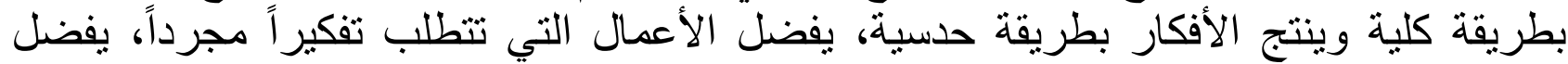
النشاطات التي تتطلب التأليف و التفكير، برتجل ما لديه من معطيات، يفضل الحصول لإل على فكرة عامة، يوجه المشاكل بجدية.

الجانب الأيسر من الدماغ: يفضل الثرح المرئي، يستخدم اللغة للتنكر ، يعالج المعلومات بطريقة

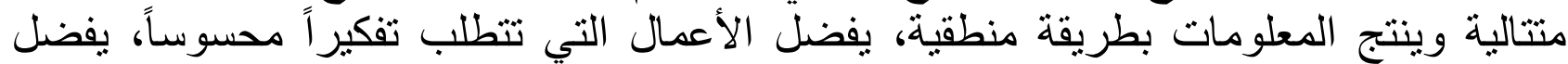

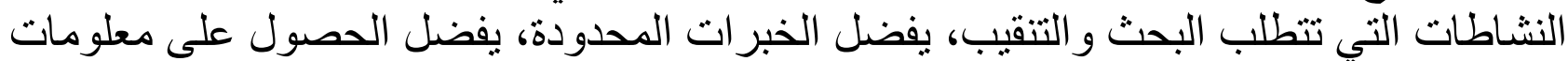
وتفاصيل دقيقة، يو اجه المشاكل بطريقة غير جادة (عامر،2015). السيطرة الدماغية وفق نموذج هيرمان

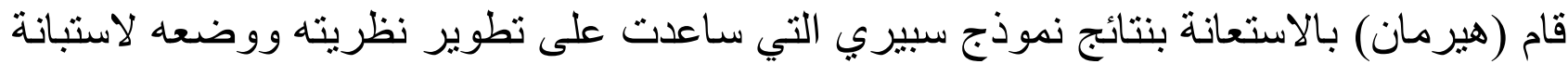

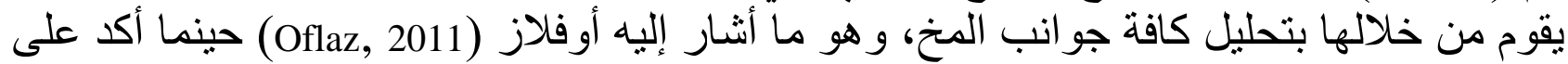

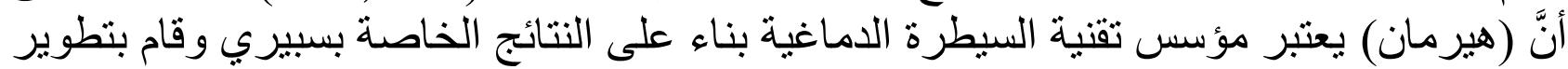

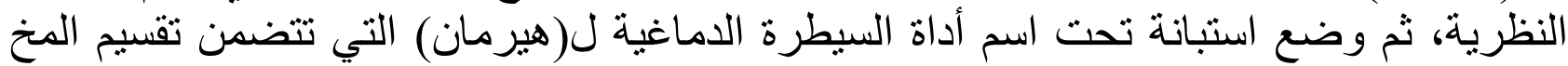

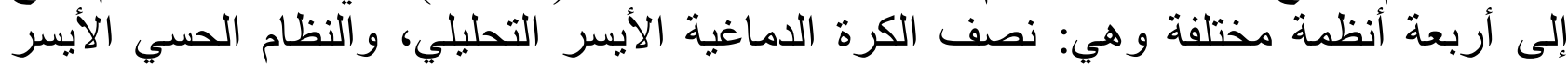

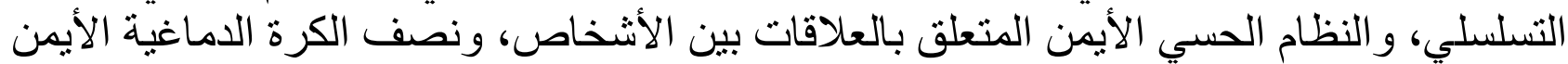
التخيلي.

وتعد نظرية الدماغ الكلي (Whole Brain Theory) ل(هيرمان) واحدة من النظريات التي تسلط

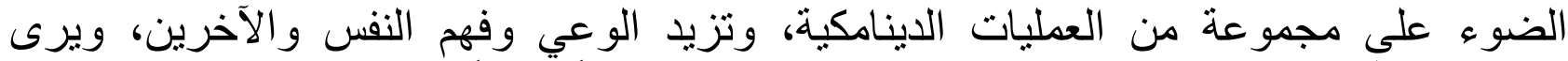

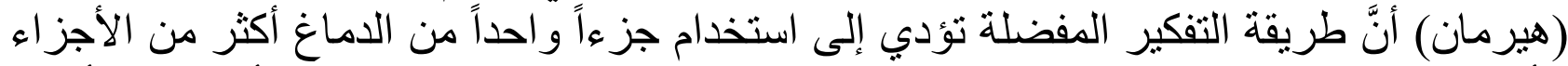

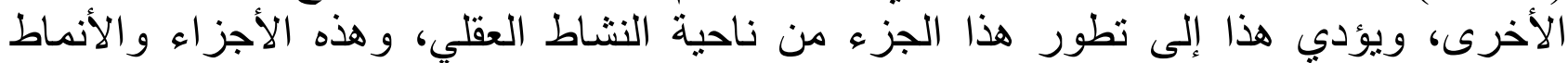

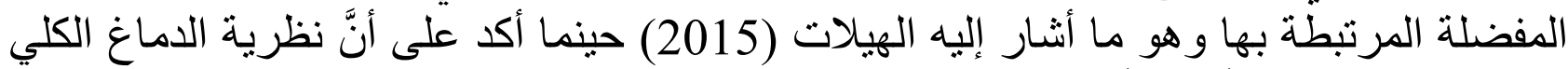

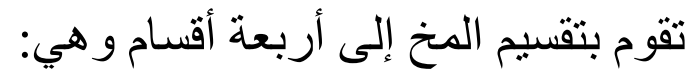

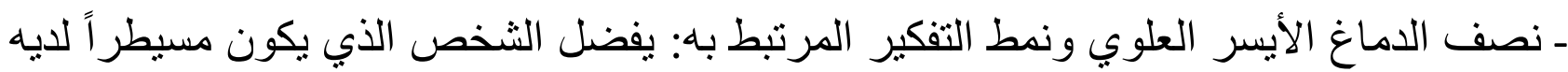

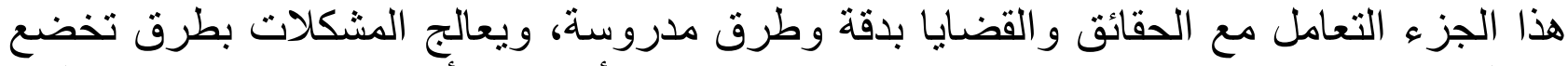
للمنطق و العقلانية والدقة، و التعامل مع التقاتليات، ويميل للأفكار والأحداث البعيدة عن العاطفة،

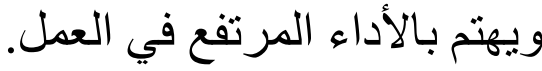

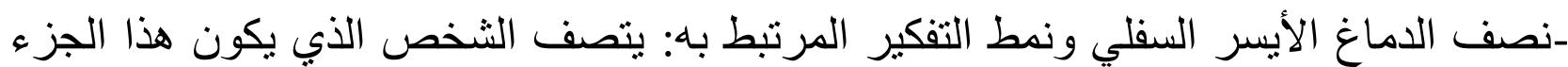

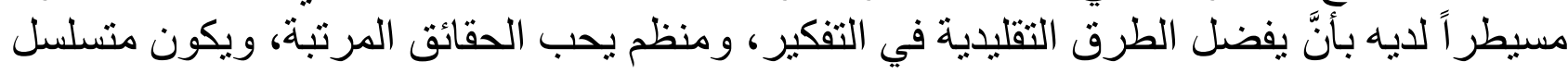


يفضل التعامل مع الأثياء و الأفكار و احدة تلو الأخرى، و أنَّ تكون بيئة العمل مستقرة وثنابتة، و هو

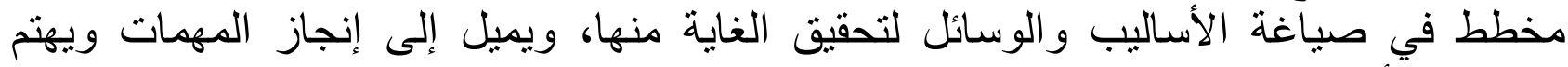
بتفاصبل الأشباء.

-نصف الدماغ الأيمن السفلي ونمط التفكير المرتبط به: يكون الشخص المسيطر عليه لديه هذا

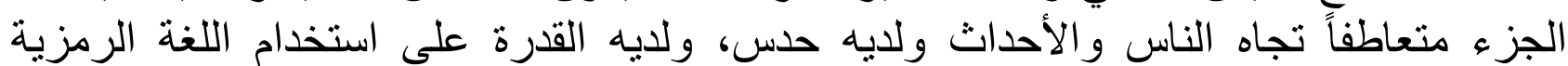
و المتمثلة بمهار ات الاتصال عن طريق لغة الجسد، ويثعر بالتعاطف تجاه الآخرين، ويعالج المشكلات بطريقة عاطفية وليست منطقية.

-نصف الدماغ العلوي الأيمن ونمط التفكير المرتبط به: يمتاز الثخص الذي يكون مسيطراً لديه

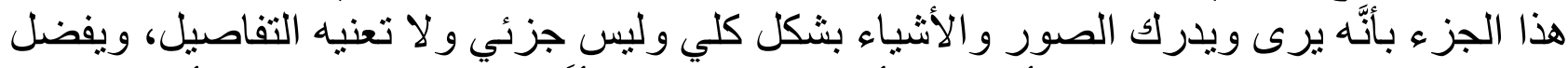

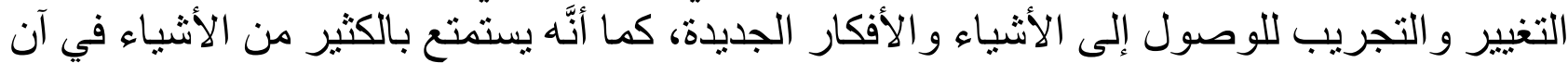

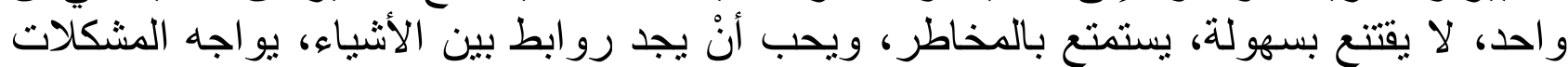

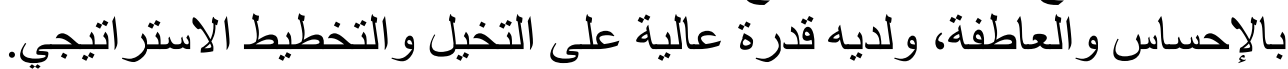
و هنا يشير السيد وشهاوي وسيد (2013) إلى أنَّ نموذج (هيرمان) يوضح وجود أربعة أنماط أو

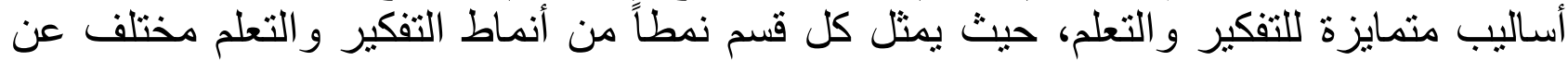
النمط الآخر، ولكنه مساوي لله في الأهمية، وذلك من خلال الامدج بين نمطي السيادة المخية

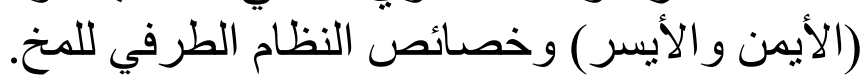

يتم من خلال نموذج (هيرمان) تقسيم المخ إلى أربعة أقسام، يعمل كل منها على تفسير جانب معين

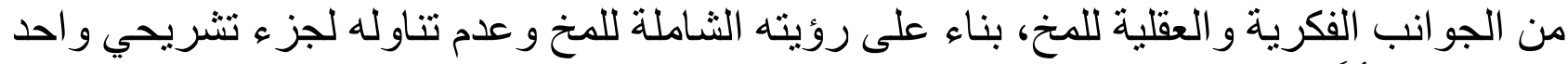
فقط؛ ويُذكر أنَّ هذا النموذج قد تم استقاء مفاده من نتائج دراسات (روجر سبيري)، و هو ما يوضح

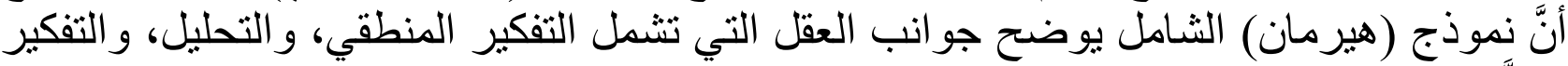

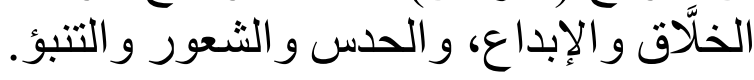

قراعة وثفير نموذج هيرمان

يُعدّ نموذج (هيرمان) بأنَّه مقياس دقيق وشامل للتفكير، فهو يقسم الدماغ لتاثلة أقسام و المخ لأربعة

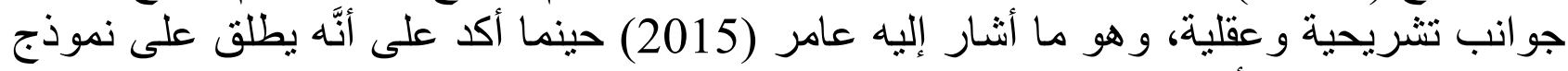

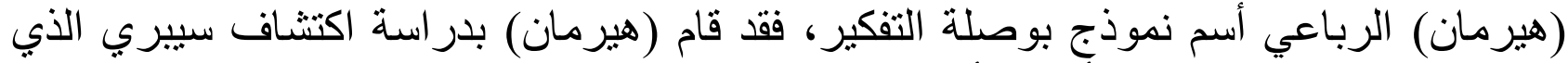
يقول بوجود جانبين للدماغ (أيمن وأيسر) ولكل منهما مهامه الخاصة، ودر اسة اكتشاف ماكلين الذي يقول بوجود ثنلاثة أدمغة في الإنسان بعضها فوق بعض، وبعد تطوير (هيرمان) لنظريته

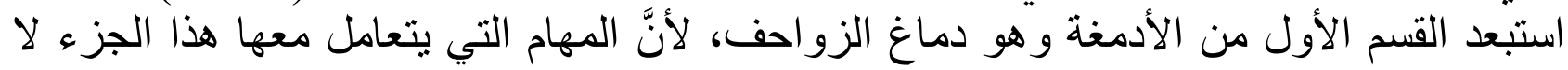

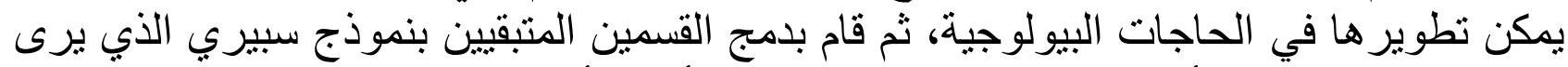

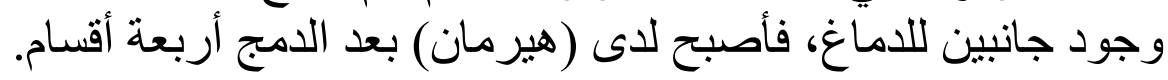

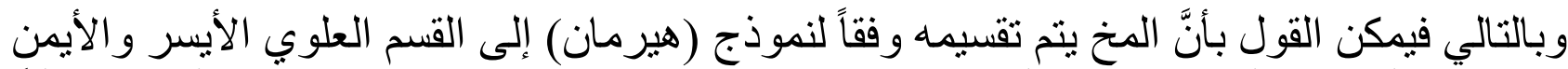

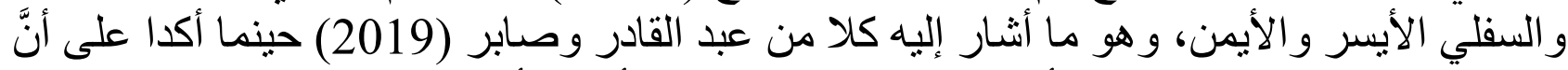

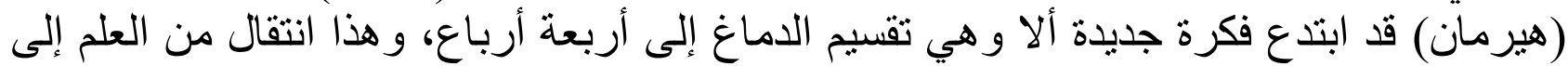

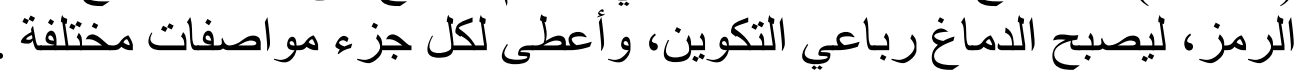
من جانبه فيثير أوزغان و آخرون (Özgena et al., 2011) إلى أنَّ (هيرمان) عمد إلى صباغة 
نموذج رباعي يقوم على تقسيم المخ إلى أربعة أرباع عام 1995، حيث يشار إلى الربع الأيسر

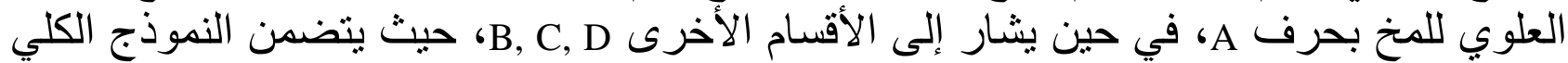

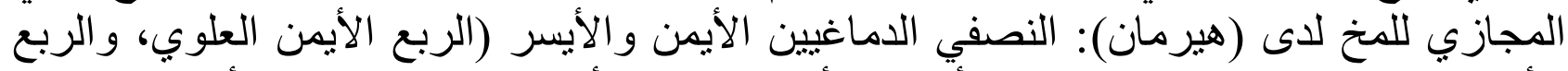

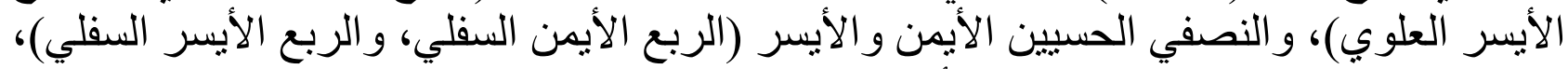

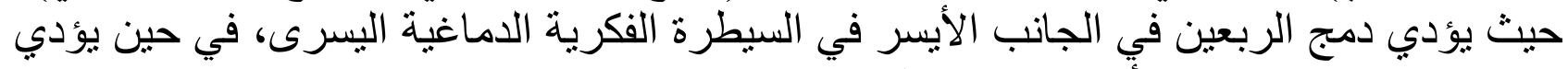

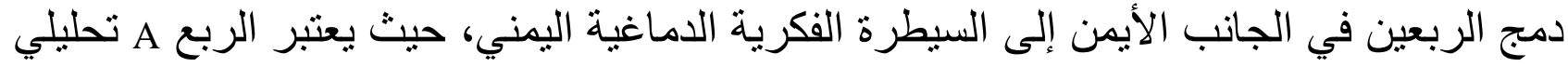

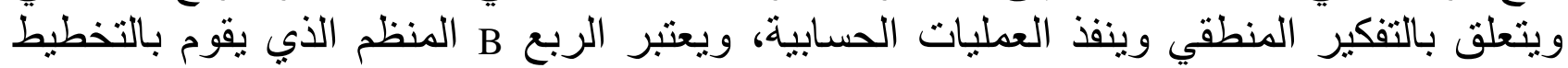

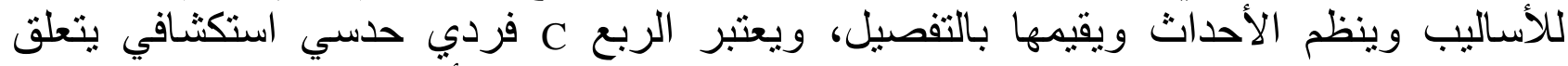
بالتعامل مع العلاقات البشرية، والربع D التخيلي الذي يصور التئي الأحداث ويقدم التخيل الفعال و التفكير واسع النطاق.

\section{نماذج ونظريات أنماط التفكير}

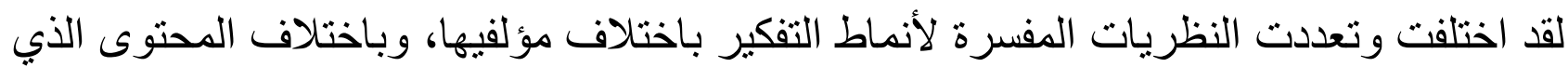

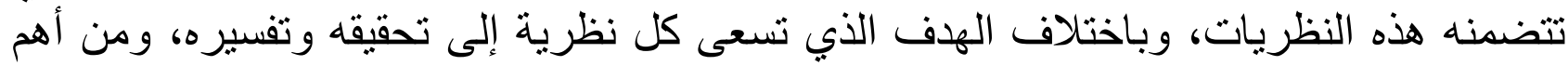

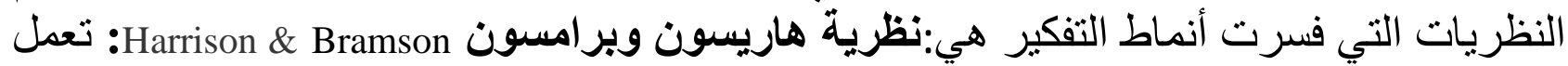

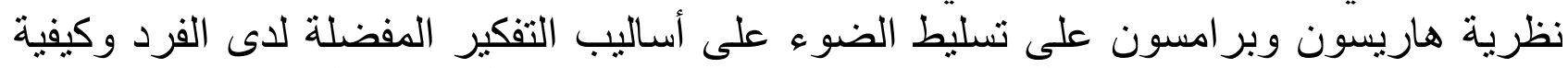

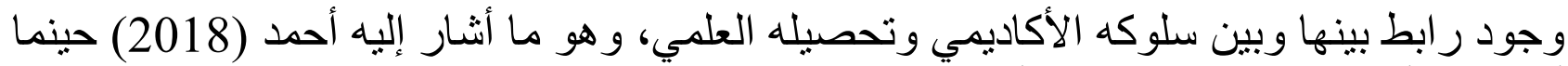

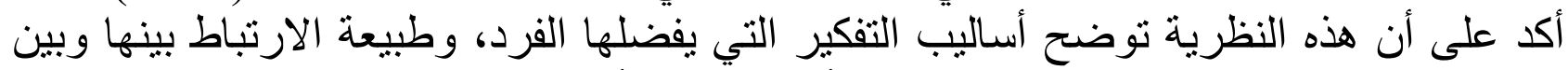

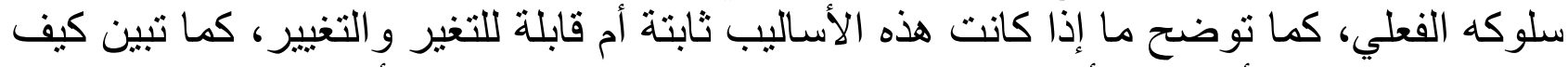

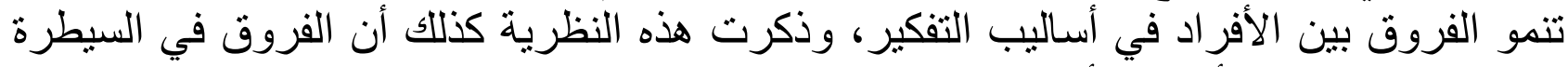

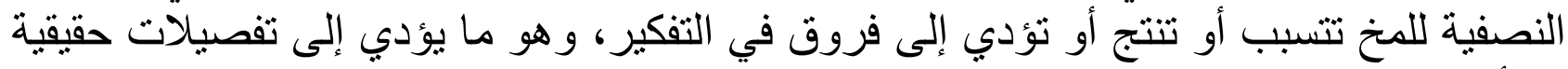
في أنماط التقكير. تصنيف تورانس Thinking Style By Torrance: يعد نورانس هو أول من استخدم نمط التعلم

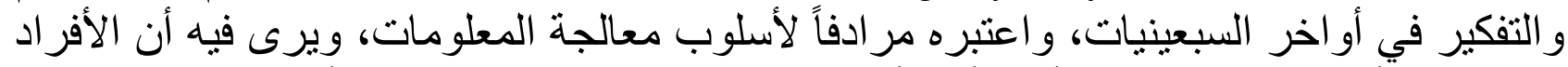

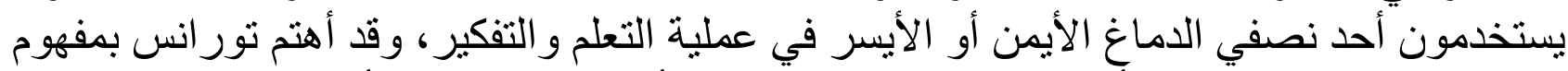

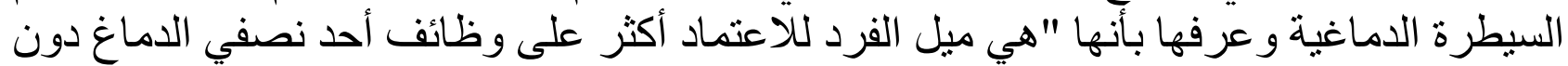

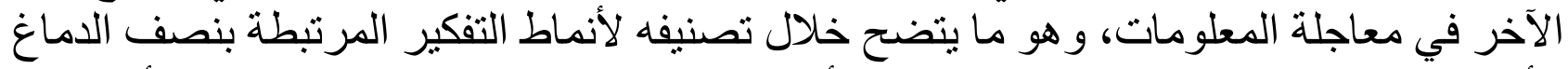

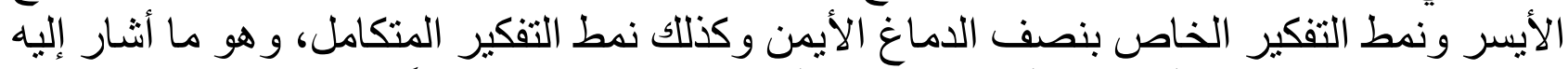
الهيلات (2015) حينما أكد على أن هناك ثلاثثة أنماط مختلفة للتفكير تبعاً للنصف التهير المسيطر ويمكن

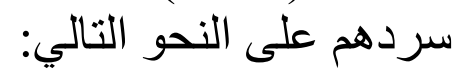

أ. ـ مط التفكير المرتبط بنصف الدماغ الأيسر ، حيث يميلون الأفراد ذو النمط الأيسر لأنَّ يكونوا

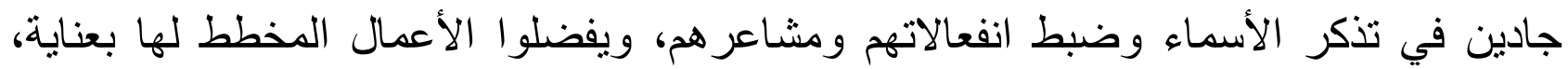

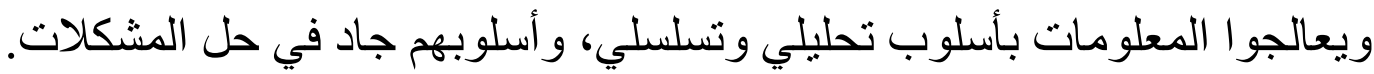

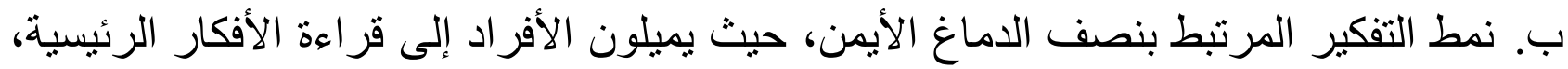

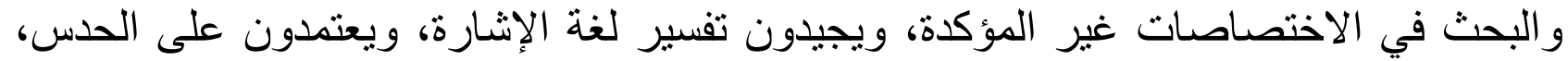

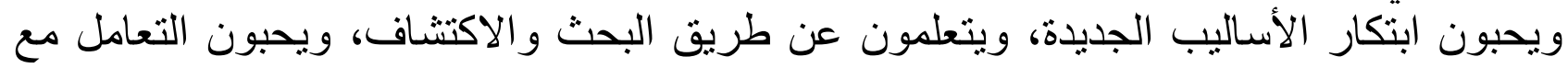

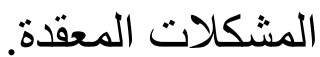


ت. نمط التفكير المتكامل، حيث يميلون الأفراد إلى استخدام وظائف كلا النصفين معاً الأيمن

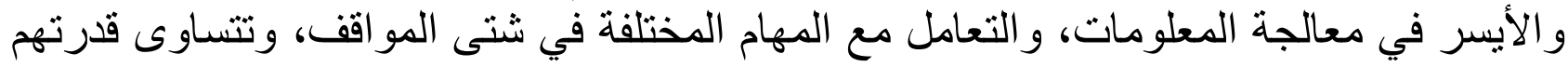

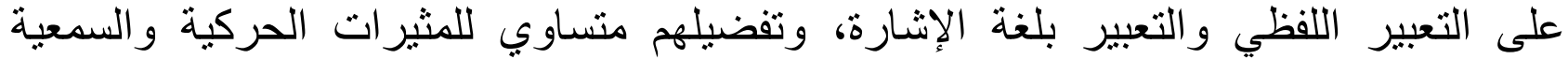

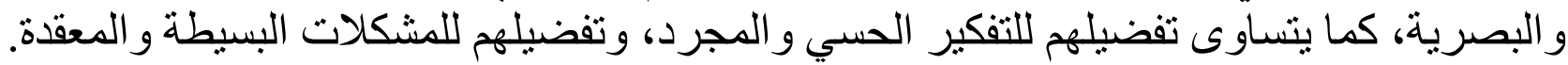

ثانياً: الار اسات السابقة:

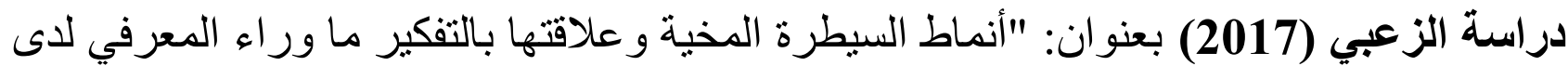

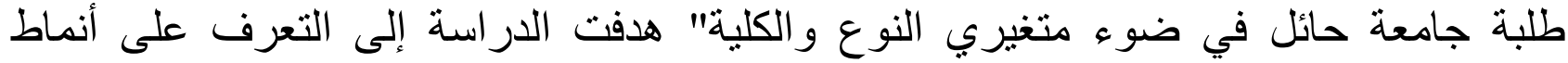

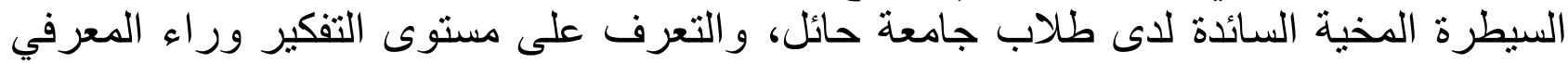

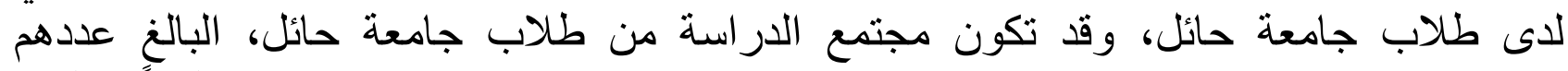

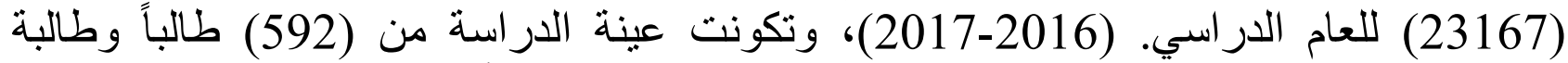

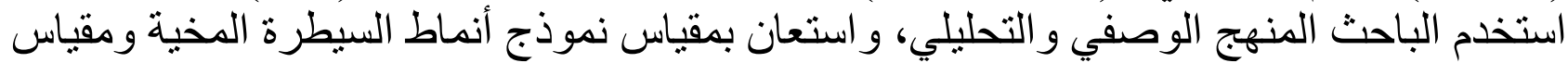

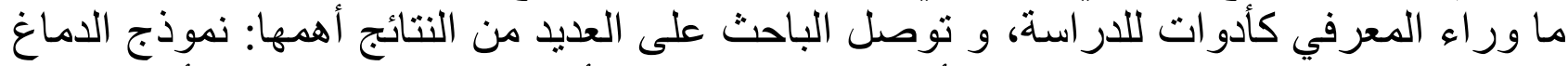

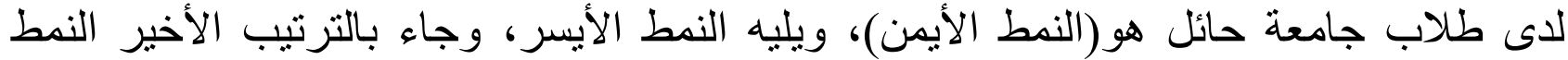

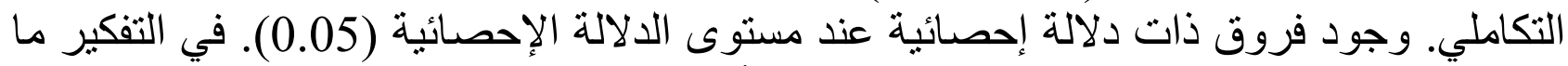

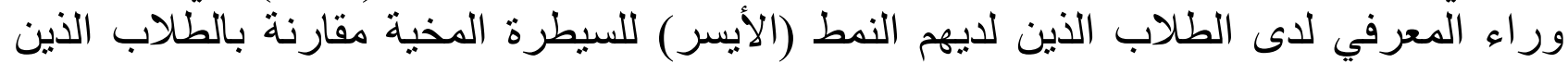
لديهم نموذج (المتكامل) للسيطرة المخية، و جاءت الفروف الفروق الإحصائية لصالح ذوي النمط (الأيسر) السيطرة المخية.

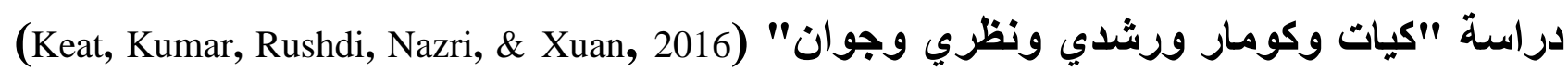

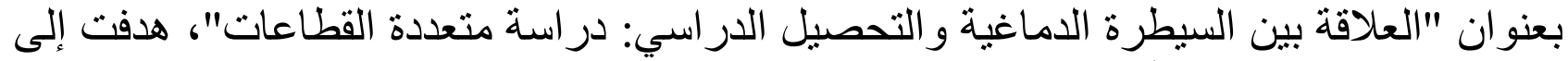

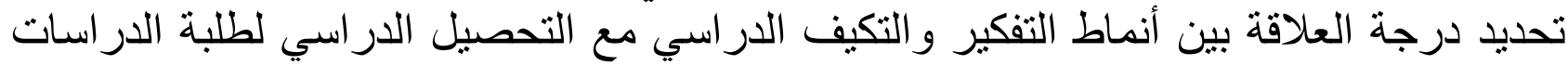

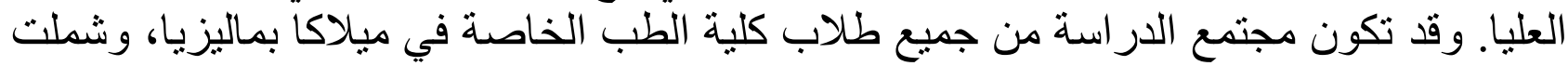

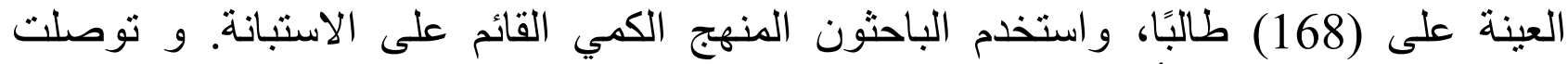

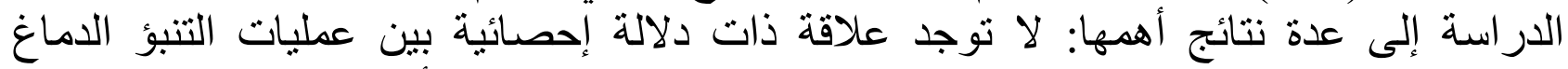

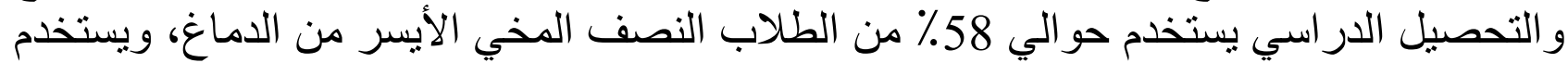

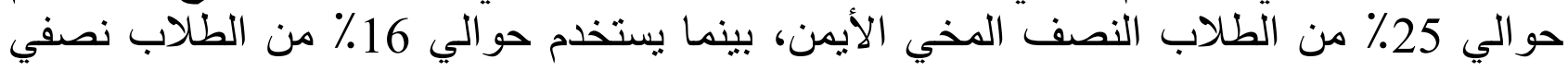

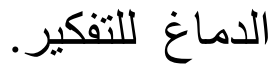

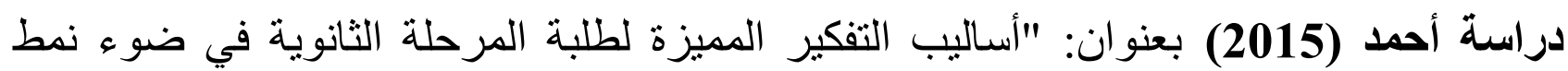

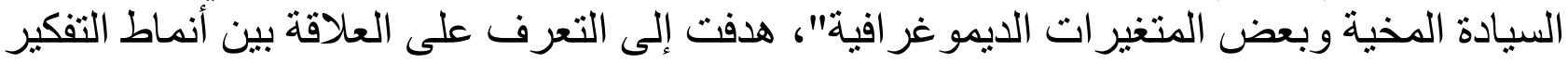

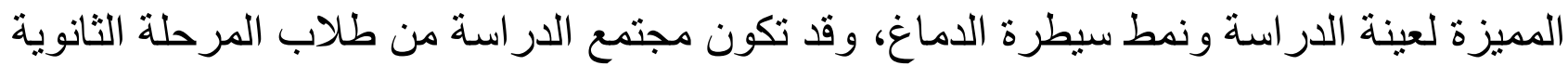

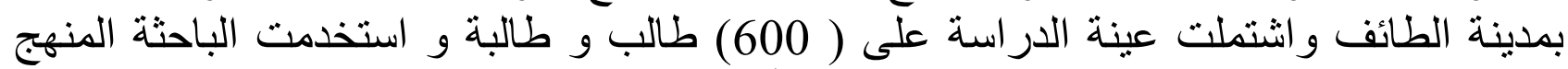

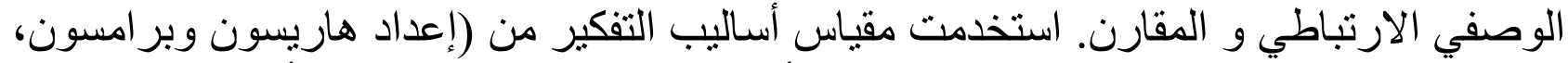

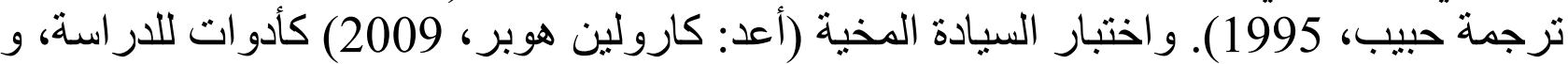

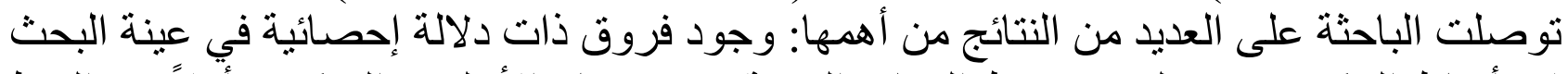

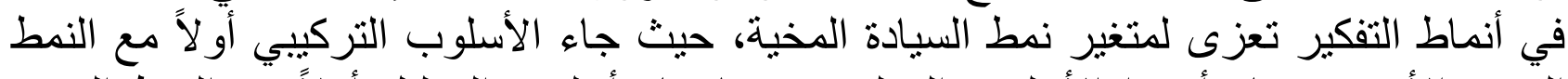

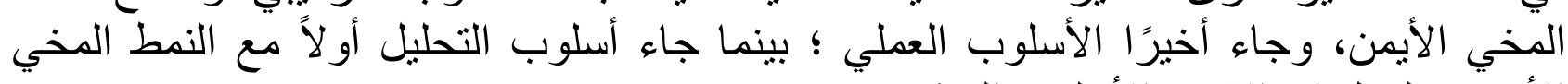
الأيسر و ليحل في الاخير وحاء الأسلوب الأبلركيبي. 


\section{منهجية البحث و إجراع|ته:}

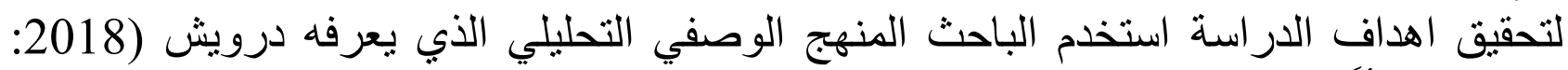

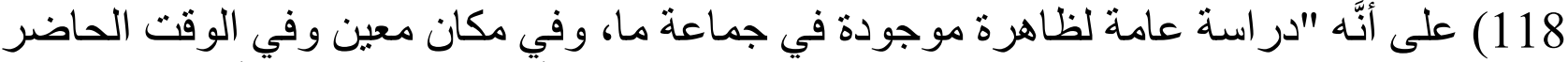

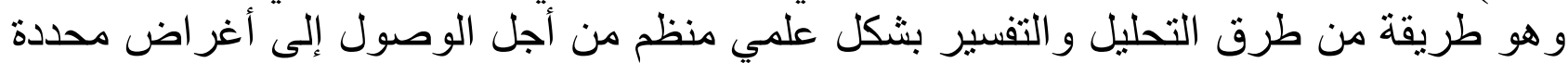
لوضعية اجتماعية أو مشكلة اجتماعية أو سكان معينين".

مجتمع البحث و وعينته:

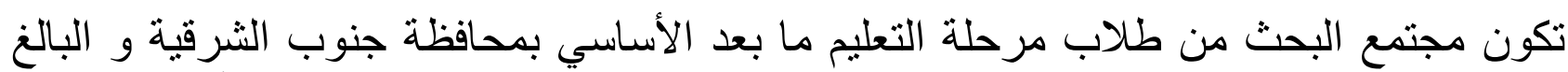

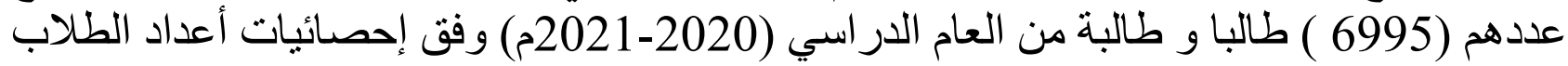

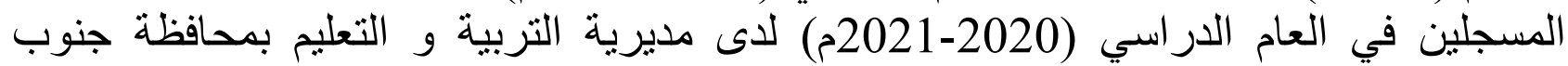

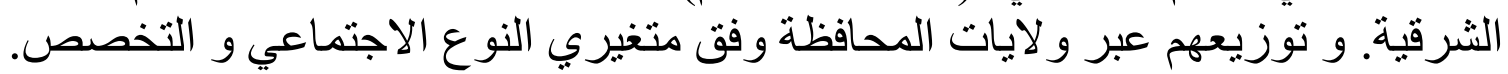

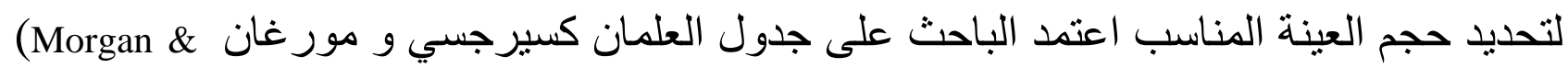
ومrejcie)

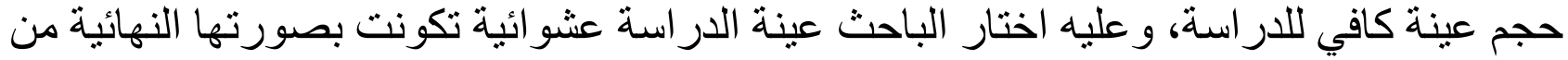
(654)، منهم ( 336) طالباو (318) طالبة.

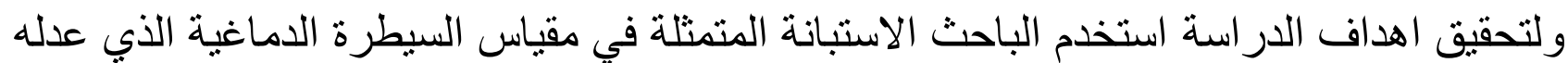

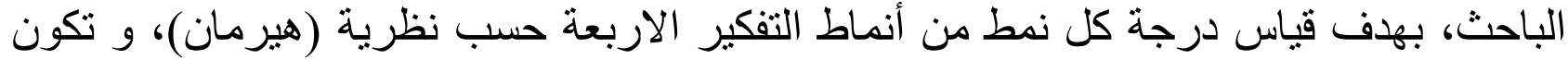

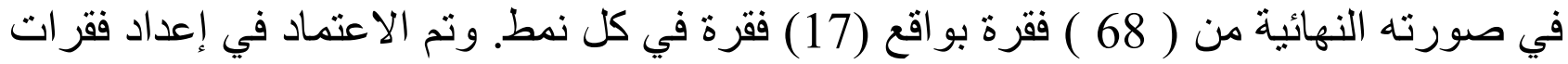

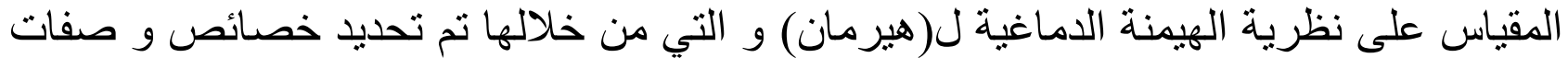

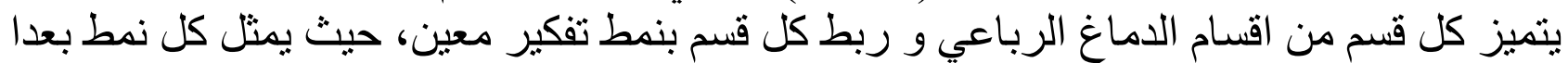

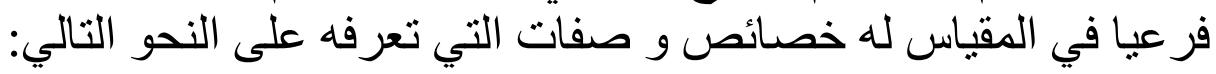

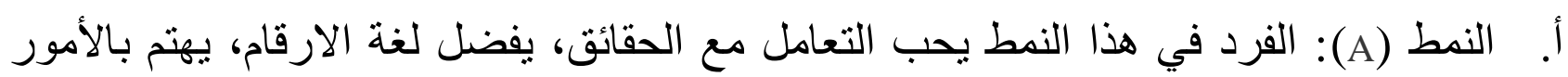
التقنية، يستخدم التحليل والتعليل في معالجة القضايا، عقلاني في قر ار اته، يحل مشكلاته بالمنطق، بيتعد عن الحسس و العاطفة.

ب. النمط (B): الفرد في هذا النمط، يفضل التفكير التقليدي، يهتم ويرتب و ينظم اغر اضهاه، يفضل

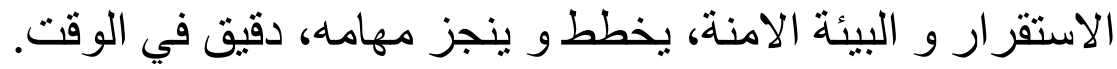

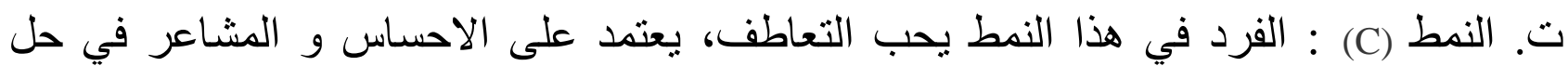

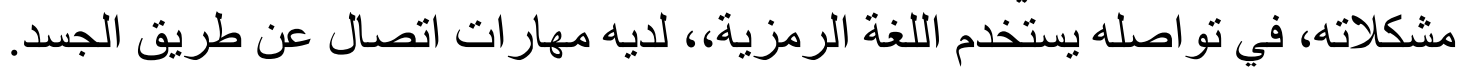

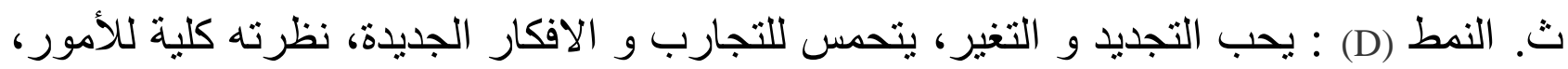

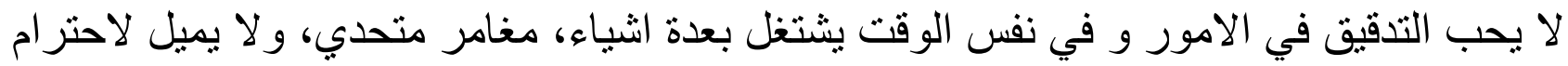
القو انين.

\section{الخصائص السيكومترية و اشتقاق المستويات المعيارية:}

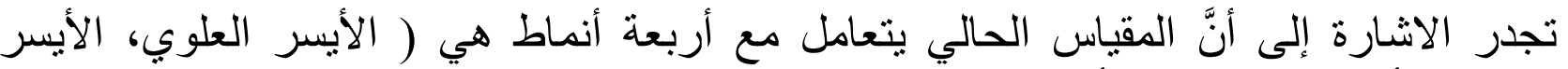

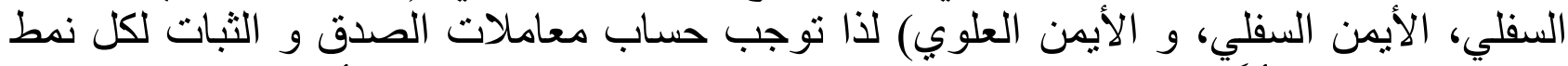

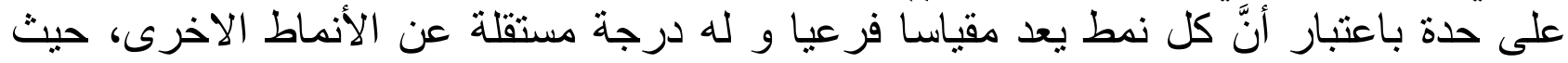




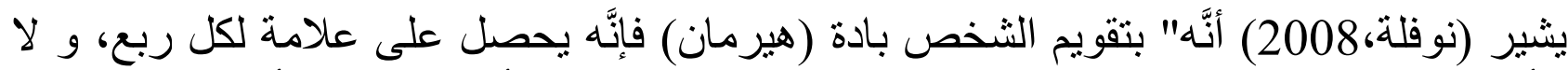

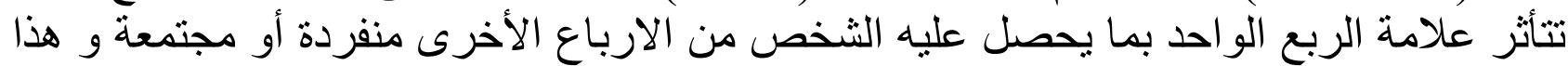

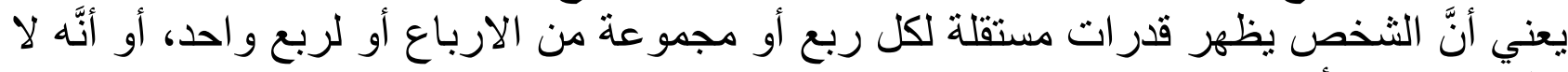
يظهر قدر ات لأي ربع".

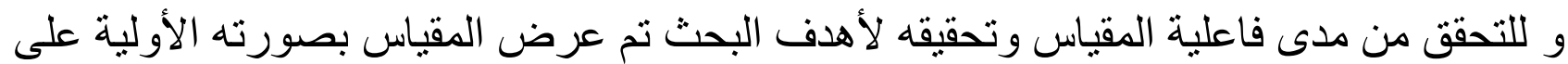

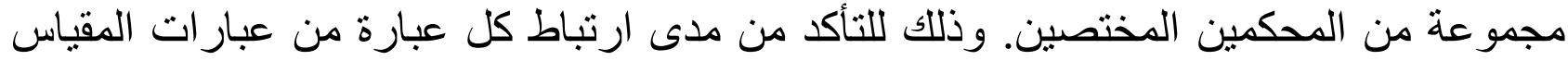

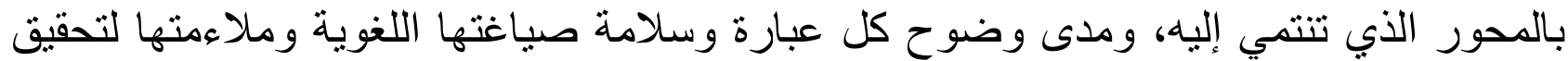

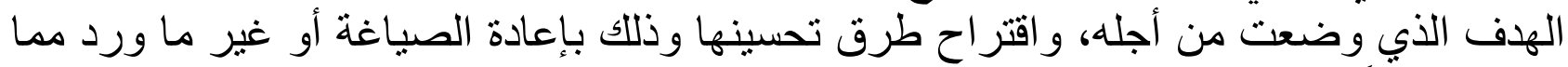
يرونه مناسبًاً.

و للاتحقق من صدق الاتساق الداخلي يرى بن صنافي (2013: 19) أنَّه "معامل الارتباط بين درجة الإنة

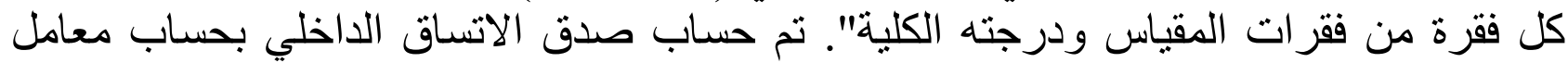

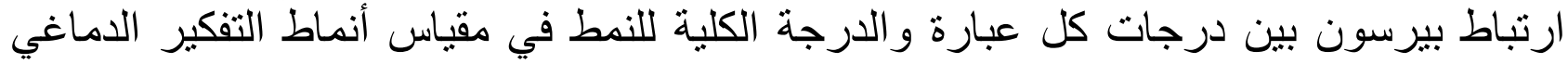

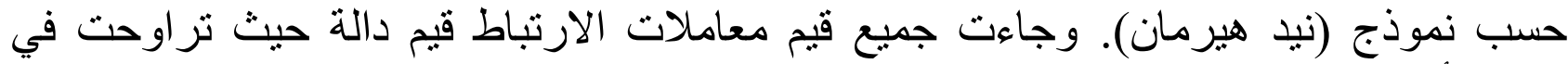

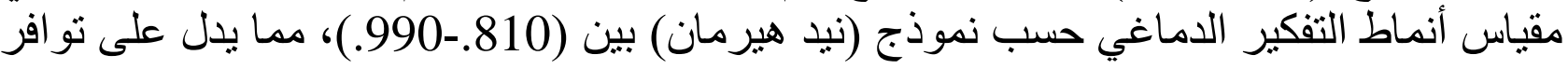
درجة عالية من صدق الاتساق الداخلي للمقياس.

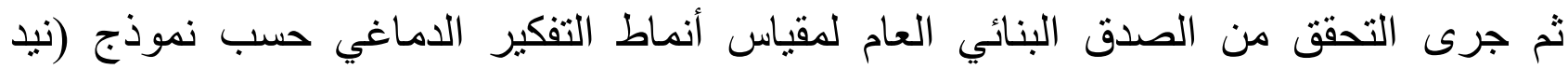

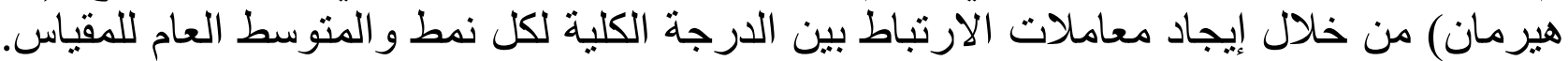

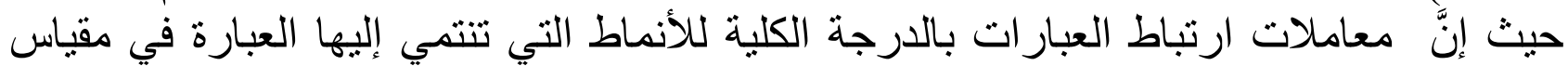

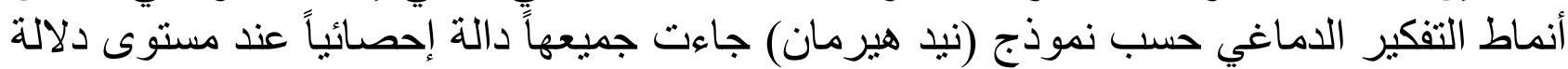

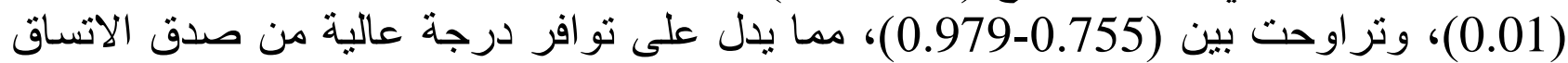
الداخلي لمقياس أنماط التفكير الدماغي وفق نموذج (نيد هير هيرمان).

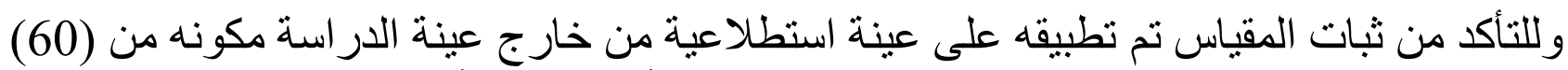

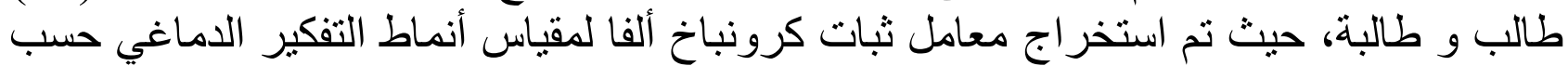

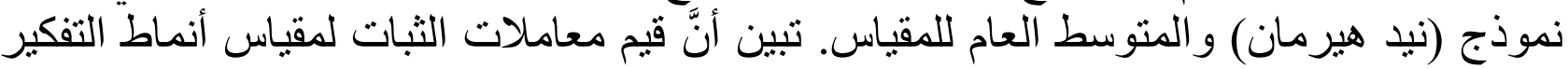

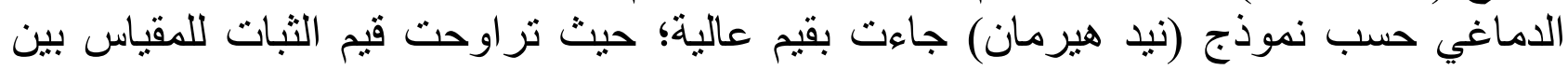

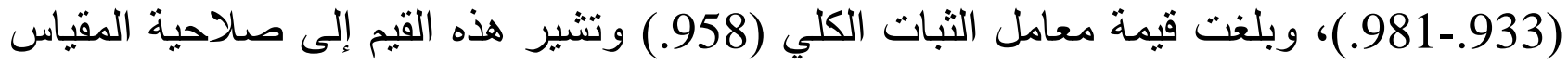

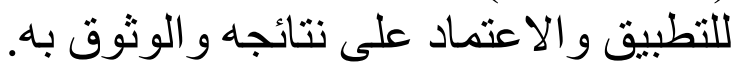

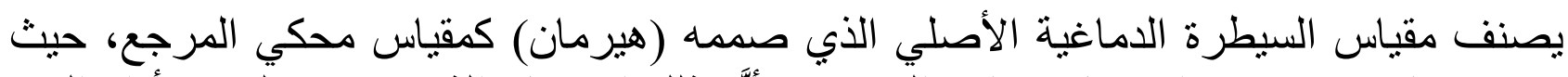

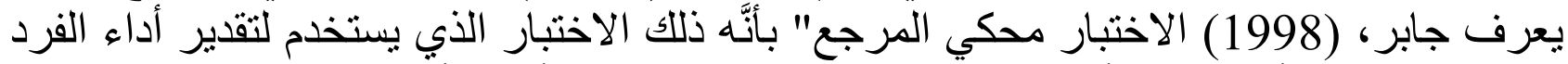
باللنسبة إلى محك أو مستوى أداء مطلق دون الحاجة الحار إلى موازنة أدائه بأداء الآخرين.

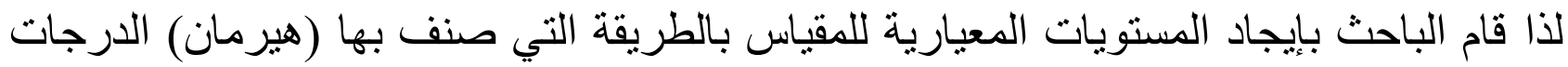

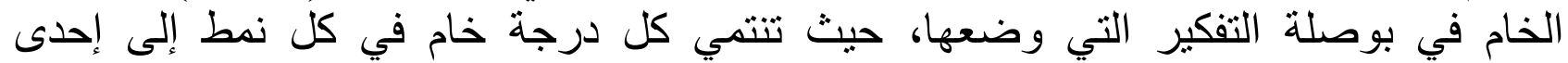

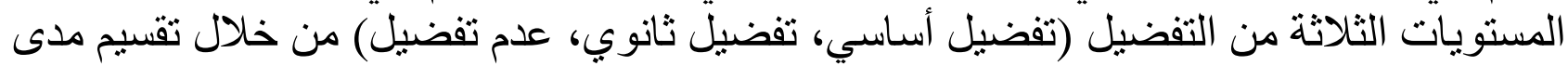

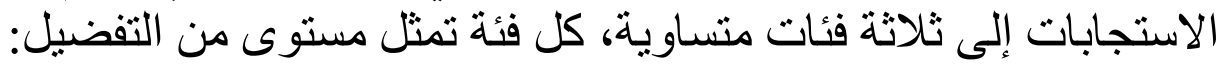
من 17 إلى39: يدل ذلك على عدم التفضيل لهذا النمط من التفكير. 
من 40إلى 62 : يدل ذللك على التفضيل الثانوي لهذا النمط من التفكير. من 63 إلى 85 : يدل ذللك على التفضيل الأساسي لهذا النمط من التفكير (سيطرة قوية لهذا النمط). نتائج البحث: ينص السؤال على الآتي: ما أنماط التفكير الدماغي السائدة لدى طلبة التعليم ما بعد الأساسي في

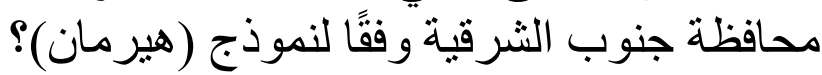

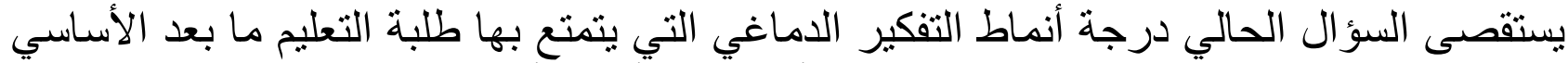

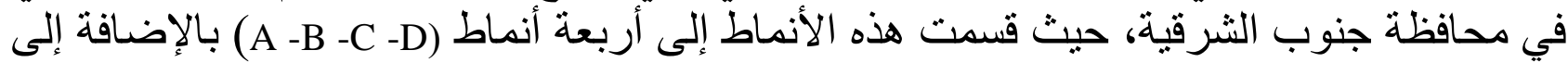

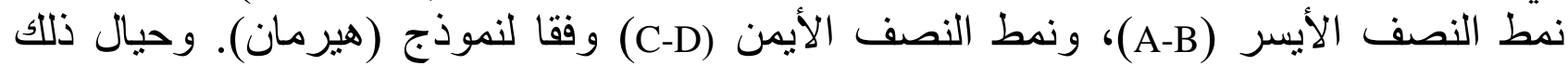

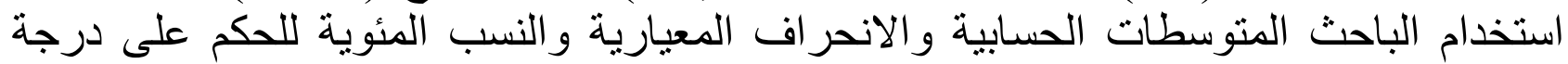
التفكير الدماغي عند عينة الدراسة.

الجدول(1) مستويات أنماط التفكير الدماغي عن أفر اد عينة الدر اسة (ن= 654)

\begin{tabular}{|c|c|c|c|}
\hline النسبة المئوية \% & التكرارات & أنماط التفكير & مستوى النمط \\
\hline 4.59 & 30 & $\mathrm{~A}$ & \multirow{10}{*}{ 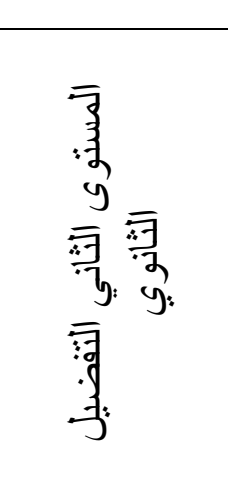 } \\
\hline 1.83 & 12 & B & \\
\hline 0.76 & 5 & $\mathrm{C}$ & \\
\hline 2.29 & 15 & $\mathrm{D}$ & \\
\hline 0.31 & 2 & $\mathrm{AD}$ & \\
\hline 0.15 & 1 & $\mathrm{AC}$ & \\
\hline 0.15 & 1 & $\mathrm{BD}$ & \\
\hline 0.61 & 4 & ACD & \\
\hline 0.46 & 3 & ABD & \\
\hline 11.16 & 73 & المجموع & \\
\hline 5.20 & 34 & $\mathrm{~A}$ & \multirow{15}{*}{ 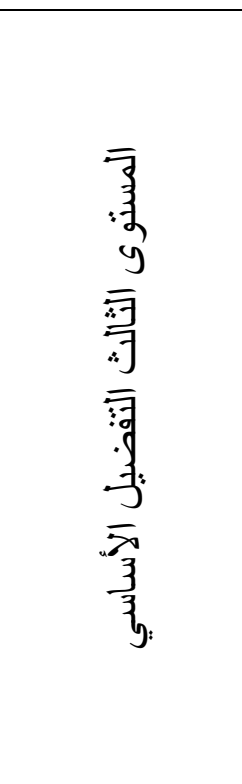 } \\
\hline 2.91 & 19 & $\mathrm{~B}$ & \\
\hline 1.38 & 9 & $\mathrm{C}$ & \\
\hline 2.45 & 16 & $\mathrm{D}$ & \\
\hline 14.07 & 92 & A-B & \\
\hline 1.07 & 7 & A-C & \\
\hline 1.99 & 13 & A-D & \\
\hline 0.76 & 5 & B-D & \\
\hline 1.07 & 7 & C-D & \\
\hline 7.34 & 48 & A-B-C & \\
\hline 6.42 & 42 & A-B-D & \\
\hline 2.75 & 18 & A-C-D & \\
\hline 2.14 & 14 & B-C-D & \\
\hline 39.30 & 257 & A-B-C-D & \\
\hline 88.84 & 581 & المجموع & \\
\hline$\% 100$ & 654 & المجموع الكلي & \\
\hline
\end{tabular}

أظهرت النتائج في الجدول رقم (1) أنَّ المجموع الكلي لعدد الطلبة المستجيبين لمقياس أنماط

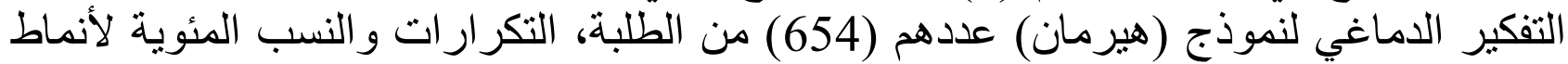


التفكير الدماغي حسب الأنماط السائدة لدى طلبة التعليم ما بعد الأساسي لمحافظة جنوب الثرقية، أنَّ عينة الدر استة انقسمت إلى مستوبين من أصل ثلاثث مستويات ـكما تم تصنيفه سابقا_أحدهما المستوى الثاني: التفضيل الثانوي، والآخر المستوى الثالث: التفضبيل الأسـاسي. وقد بلغ عدد الطلبة المصنفين في المستوى التفضيل الثانوي (73) بنسبة مئوية بلغت (11.16\%)، وتحتل الترنيب الأبن

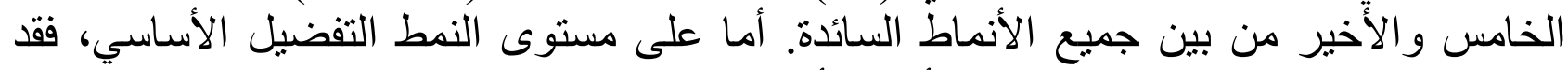
تركزت التكرارات في المستوى ذو الأربعة أنماط سائدة، حيث بلغ عدد الطلبة (257)، بنسبة منية

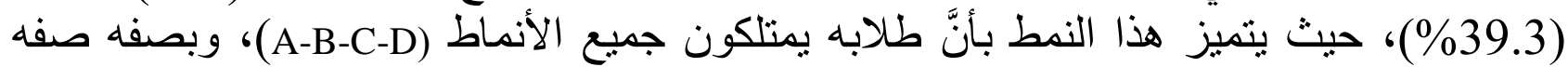
أساسية. يلي هذا النمط الطلبة الذين يمتلكون نمطين سائدين على اختلاف نوع هذين النمطين، وقد بلغ عدد الطلبة في هذا المستوى (124). واحتل المركز الثالث الطلبة الذين يمتلكون ثلاثنة أنماط سائدة بفارق طالبين عن المركز الثاني. بينما الطلبة الذين بمنلكون نمطا و احدا سائدا جاء في

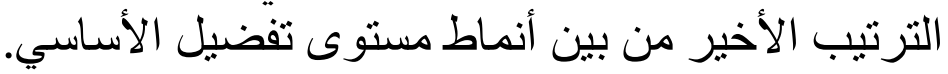

مناقشية النتائج

يتضح من الجدول (1) مستويات أنماط التفكير الدماغي السائدة لأفراد العينة و هي على النحو التالي:

أولا: أظهرت التكرارات والنسبة المئوية للمستوى الثاني (التفضيل الثانوي) الذين حصلوا على درجات حسب المستويات المعيارية بين (40-62) بلغ (73) من الطلبة، ويثكلون نسبة (1\%11.16) من مجموع الطلبة.

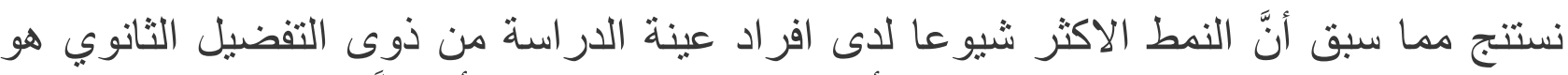

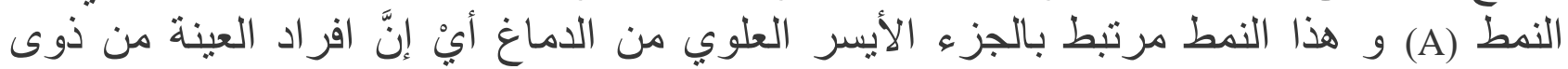

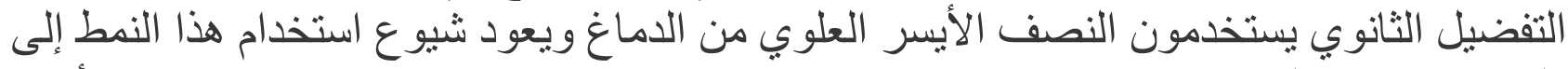
طرق و اساليب طرح المعلومات و التي تركز على العمليات العقلية التي يختص بها الجزء الأئ الأيسر العلوي من الاماغ

Keat, Kumar, Rushdi, ) "تنفق هذه النتائج مع نتائج در اسة "كيات وكومار ورشدي ونظري وجوان و قد توصلت الدر اسة إلى العديد من النتائج كان من أهمها. يقوم حو الي ورجي

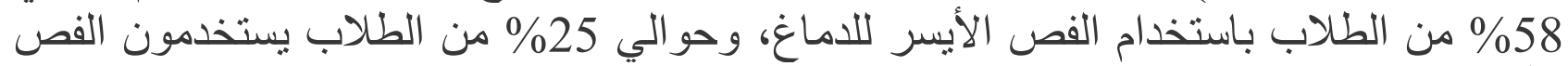
الأيمن من الدماغ، بينما يستخدم حو الي 16\% من الطلاب نصفي الدماغ في التفكير. تؤكد هذه النتائج سيطرة النصف المخي الأبسر في معظم عينة الدراسة من ذوي (التفضيلات

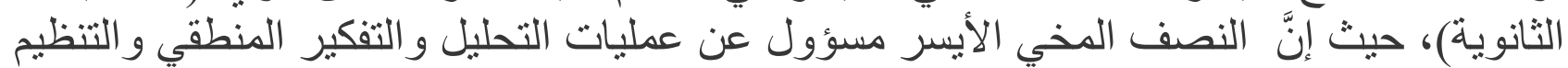
و التسلسل و الحساب، حيث إنَّ هذه الوظائف هي الأساس الذي يقوم عليه الكثير من المعلّمين بيناء

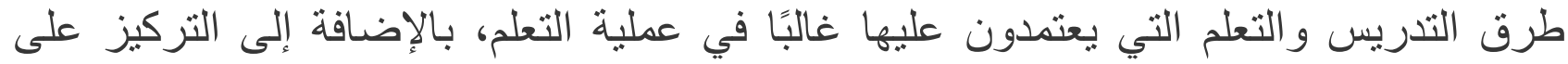
طريقة التلقين والتركيز على المنطق، بينما يتم تجاهل جوانب التبادئ المبادرة والمرونة والعاطفة و استخدام الاستر اتيجيات الإبداعية. العملية التعليمية و التي ساهمت بشكل مباشر في زيادة نشاط الدماغ الأيسر، حيث تهدف استر اتيجيات التدريس في المدارس الحالية في بعض المناهج الدراسية اسية إلى تطوير النصف المخي الأيسر فقط من خلال تركيز الأنثطة التعليمية على الدماغ. اللغية فئة و التفكير المنطقي و الرياضي و السببي. 
يمكن للباحث أنْ يعزو هذه النتائج إلى افتقار المعلمين للتنوع في أساليب التدريس وتخلئهم عن

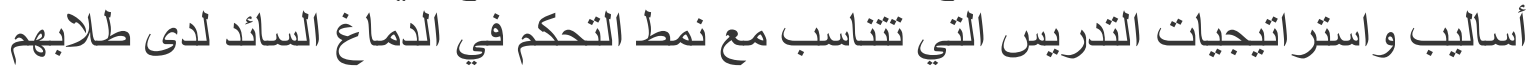

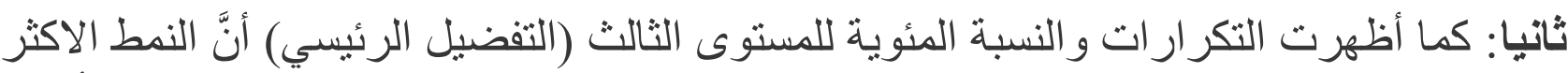

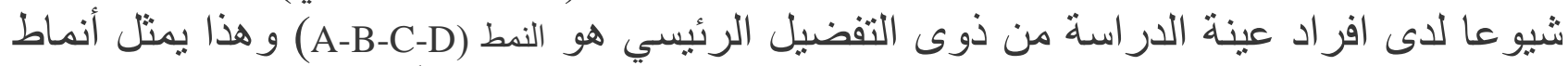

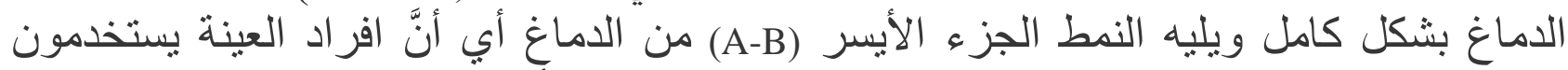

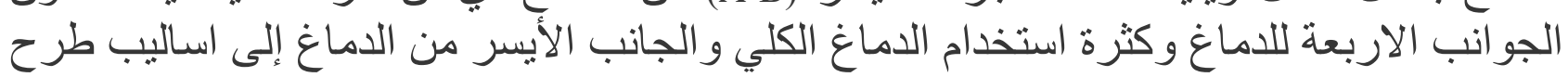

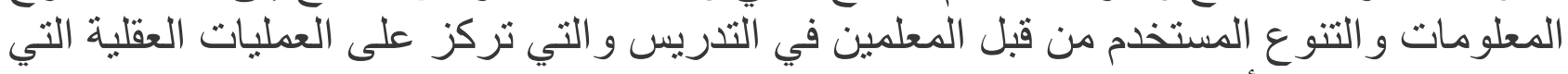
يختص بها الدماغ بأجز ائه الاربعة.

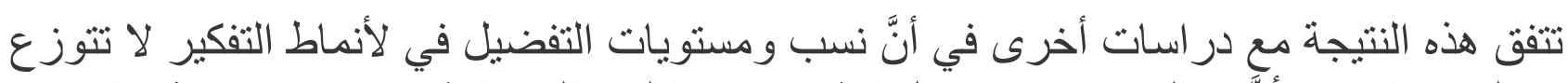

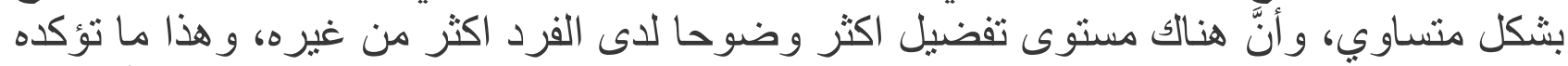

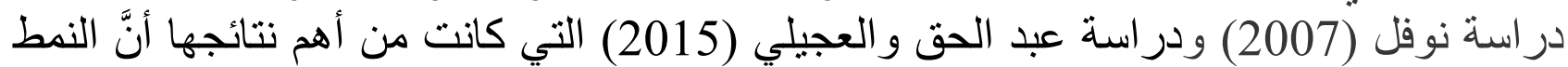

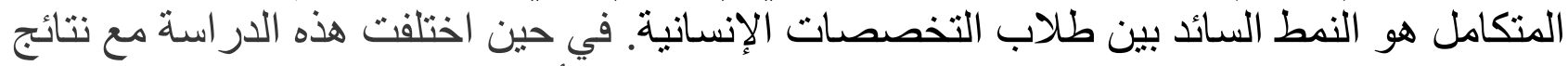

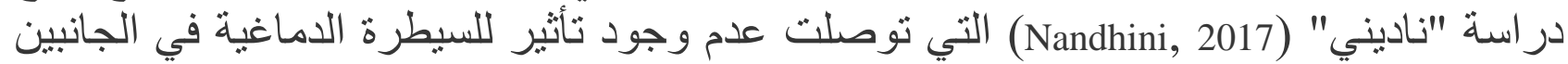
الأيمن و الأيسر على التحصيل الدر اسي لدى طلاب المدارس الثانوية.

وقد يفسر الاختلاف بين الدراسات لتفضيل أنماط التفكير حسب التبافي (هيرمان) من حيث الاكثر

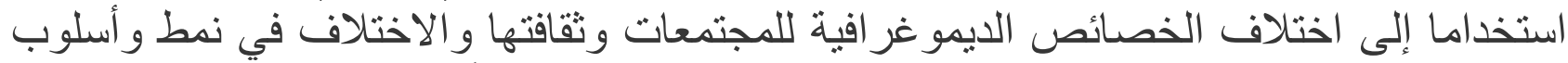

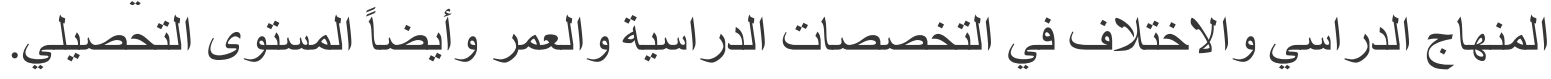

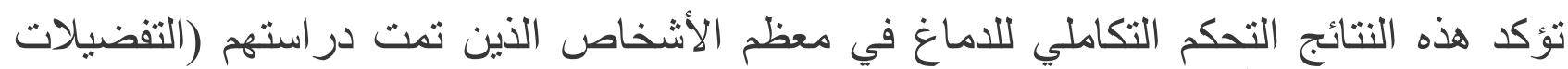

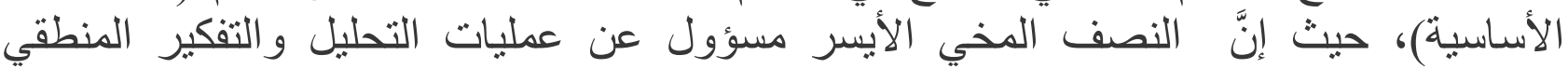

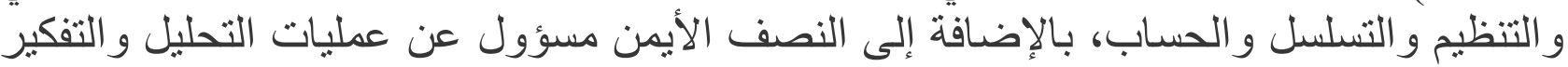

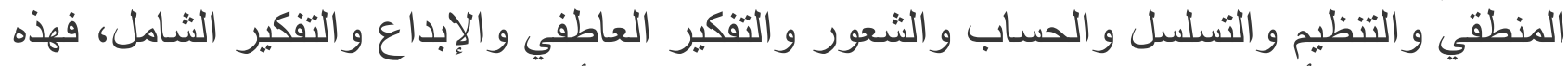

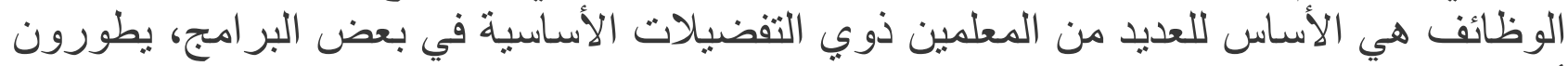

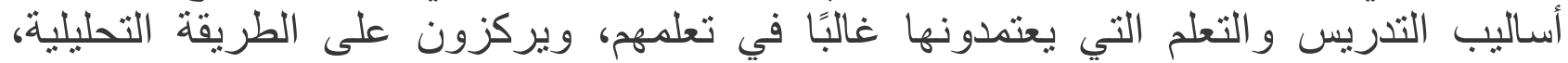

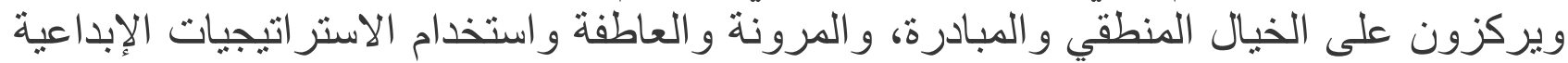

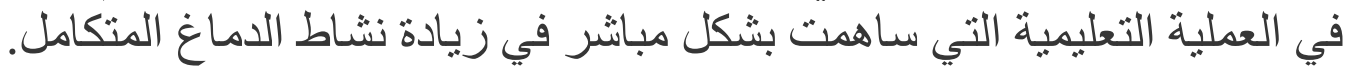
يمكن للباحث ربط هذه النتائج بتكييف وتدريب المعلمين وفقًا لنماذجهم السائدة، مما ينتج عندئه

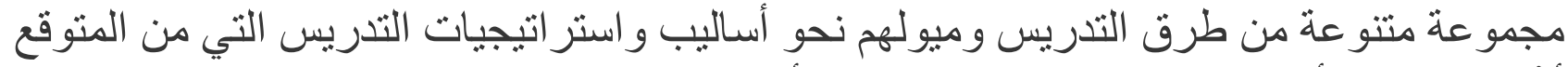

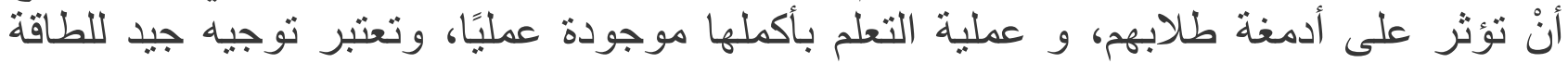

الاماغ.

قائمة المراجع

إبر اهيم، سليمان عبد الواحد يوسف. (2013). علم النفس التعليمي: نماذج التعلم وتطبيقاته في حجرة الدراسة. عمان: دار أسامة للنشر و التوزيع.

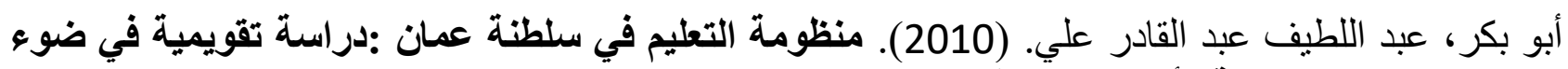

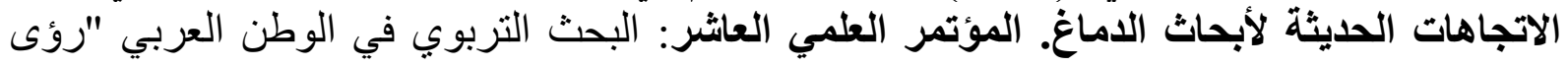


مستقبلية"، كلية التربية، جامعة الفيوم، 191-251.

بلكرد، ححم. (2017). بناء مقياس للكثف عن أنماط التفكير حسب نظرية هيرمان لائ تلاميذ السنة أولى التى

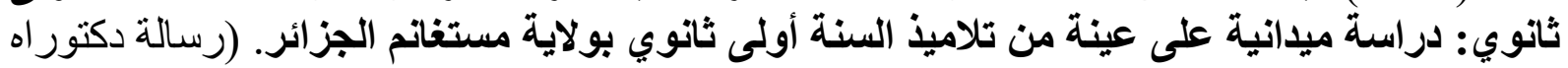

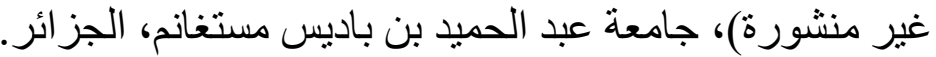
جابر، عبد الحمبد جابر(1998). التدريس والتعلم ـ الأسس النظرية ـ الاستراتيجيات والفاعلية. مصر : دار الفكر.

حجاج، ححم الأمين. (2011). العلاقة بين السيطرة الدماغية واضطراب الإدراك البصري لأى تلاميذ من ذوي صعوبات تعلم الرياضيات: دراسة نفس عصبية لحالات. (رسالة ماجستير غير منشورة)، جامعة

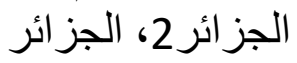

درويش، محمود أحمد. (2018). مناهج البحث في العلوم الإنساتية. مصر: مؤسسة الأمة العربية للنشر و التوزيع.

الر ابغي، خالد بن ححم بن محمود. (2015). عادات العقل ودافعية الإنجاز. عمان: مركز ديبونو لتعليم التفكير. زنقور، ماهر حمح صالح. (2017). بيئة الصف المقلوب لتنمية مهارات التفكير الحدسي ومستويات الاستدلال

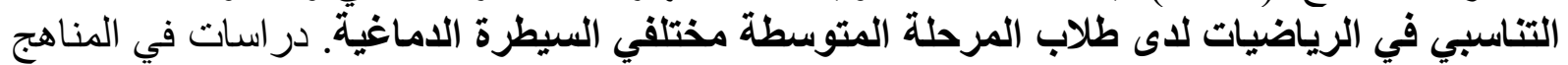
وطرق التدريس، (220)، 16-93.

السيد، منى حسن؛ الثهاوي، هناء إبر اهيم أحمد؛ سيد، أماني سعيدة. (2013). تحسين أنماط السبطرة الدماغية للأطفال ذوي اضطراب تصور الانتباه المصحوب بالنشاط الحركي الزائد ADHD.

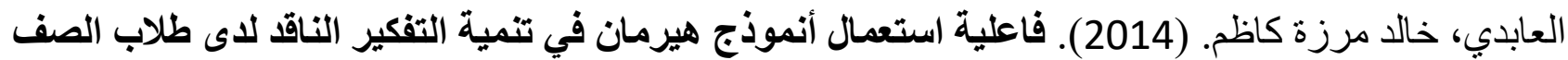
الرابع الأدبي في مادة تاريخ الحضارة العربية الإسلامية. (رسالة ماجستير غير فئمانية منشورة)، جامعة بابل،

عبد الحسين، وسام صلاح. (2015). التعلم المتناغم مع الدماغ: تطبيقات لأبحاث الاماغ مع التعلم. القاهرة: دار الكتب العلمية.

عبد الحق، زهرية؛ العجيلي، صباح. (2015). السيطرة الاماغية وعلاقتها بالتفكير الإبداعي لاى طلى الإبة

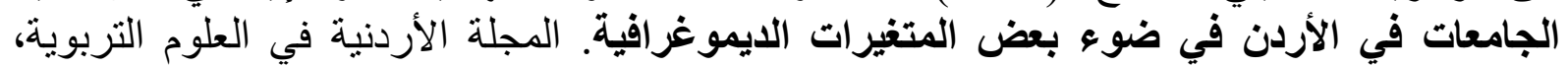

254-239، (2)11

عبد القادر، اسماعيلي يامنة؛ صابر، قثتوش. (2019). الدماغ والعمليات العقلية "الانتباه والإدراتك والتفكير

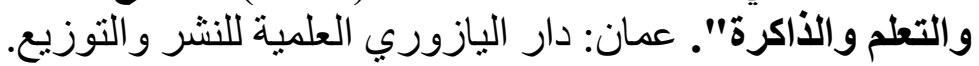

عوض، عباس محمود (1989). علم النفس العام. الإسكندرية :دار المعرفة الجامعية. الهمان، أمل فلاح فهد. (2013). الهيمنة الدماغية وعلاقتها بالتفضيل المهني لاى شرائح مختلفة من الطلاب في المجتمع الكويتي. (رسالة دكتور اه غير منشورة)، جامعة القاهرة، القاهرة. الهيلات، مصطفى قسيح. (2015). مقياس هيرمان لأنماط التفكير. الأردن: مركز ديبونو لتعليم التفكير.

\section{ARABIC REFERENCES IN ROMAN ALPHABET:}

'librahim, Sulayman Eabd Alwahid Yusuf. (2013). Eilm Alnafs Altaelimi: Namadhij Altaelum Watatbiqatuh fi Hujrat Aldirasati. Eamana: Dar 'Usamat Lilnashr Waltawzie.

Abu Bikr, Eabd Allatif Eabd Alqadir Ealay. (2010). Manzumat Altaelim Fi Saltanat Eamman :Draasat 
Taqwimiat fi Daw' Alaitijahat Alhadithat Li'abhath Aldamaghi. Almutamar Aleilmii Aleashr: Albahth Altarbawii fi Alwatan Alearabii "Rwaa Mustaqbaliata", Kuliyat Altarbiat, Jamieat Alfayuwm , 191-251.

Bilkrud, Mahmad. (2017). Bina' Miqyas Lilkashf Ean 'Anmat Altafkir Hsb Nazariat Hayrman Ladaa Talamidh Alsanat 'Uwlaa Thanuy: Dirasat Maydaniat Ealaa Eayinat Min Talamidh Alsanat 'Uwlaa Thanawi Biwilayat Mustaghanim Aljazayiri. (Rsalat Dukturah Ghyr Manshurata), Jamieat Eabd Alhamid Bin Badis Mustaghanim, Aljazayir.

Jabir , Eabd Alhamid Jabr(1998). Altadris Waltaelum - Al'usus Alnazariat - Alaistiratijiaat Walfaeiliatu. Masra: Dar Alfikr.

Hajjaj, Muhamad Al'amyn. (2011). Alealaqat Bayn Alsaytarat Aldamaghiat Waidtirab Al'iidrak Albasrii Ladaa Talamidh Min Dhwy Sueubat Taelam Alriyadiat: Dirasat Nfs Easabiat Lihalat. (Rsalt Majstyr Ghyr Mnshur), Jamieat Aljazayir2, Aljazayir.

Darwish, Mahmud 'Ahmud. (2018). Manahij Albahth fi Aleulum Al'iinsaniati. Masr: Muasasat Al'umat Alearabiat Lilnashr Waltawzie.

Alraabighy, Khalid Bin Muhamad Bin Mahmud. (2015). Eadaat Aleaql Wadafieiat Al'iinjaz. Eamaan: Markaz Dibunu Litaelim Altafkir.

Zunqur, Mahir Muhamad Salih. (2017). Bayyat Alsafi Almaqlub Litanmiat Maharat Altafkir Alhudasii Wamustawayat Alaistidlal Altanasbii fi Alriyadiaat Ladaa Tullab Almarhalat Almutawasitat Mukhtalifi Alsaytarat Aldamaghiati. Dirasat fi Almanahij Waturuq Altadrisi, (220), 16-93.

Alsayd, Munaa Hsn; Alshahawi, Hana' 'librahim 'Ahmad; Sayd, 'Amani Saeid. (2013). Tahsin 'Anmat Alsaytarat Aldamaghiat Lil'atfal Dhwy Aidtirab Tasawur Alaintibah Almashub Bialnashat Alharakii Alzzayid Adhd. Majalatan

Aleabidi, Khalid Mirazat Kazim. (2014). Faeiliat Aistiemal 'Unmudhaj Hirman fi Tanmiat Altafkir Alnaaqid Ladaa Tullab Alsafi Alrrabie Al'adbii. fi Madat Tarikh Alhadarat Alearabiat Al'iislamiati. (Rsaalat Majstayr Ghyr Manshurata), Jamieat Biabli, Aleiraq.

Eabd Alhusyn, Wasam Salah. (2015). Altaelim Almutanaghim Mae Aldamagh: Tatbiqat Li'abhath Aldimagh Mae Altelm. Alqahrt: Dar Alkutub Aleilmiat.

Eabd Alhaq, Zahryt; Aleajilii, Sabah. (2015). Alsaytarat Aldimaghiat Waealaqatuha Bialtafkir Al'iibdaeii Ladaa Talabat Aljamieat fi Al'urdun Fi Daw' Bed Almutaghayirat Aldiymughrafiati. Almajalat Al'urduniyat Fi Aleulum Altarbiwiat, 11(2), 239-254.

Eabd Alqadir, Aismaeili Yamnt; Sabir, Qashush. (2019). Aldimagh Waleamaliat Aleaqlia "Alaintibah Wal'iidrak Waltafkir Waltaelum Waldhaakirata". Eaman: Dar Alyazwry Aleilmiat Lilnashr Waltawzie.

Eawd, Eabbas Mahmud (1989). Eilm Alnafs Aleamu. Al'iiskandariat: Dar Almaerifat Aljamieiat.

Alhumlan, 'Amal Filah Fahd. (2013). Alhaymanat Aldimaghiat Waealaqatuha Bialtafdil Almahnii Ladaa Sharayih Mukhtalifat Min Altullab fi Almujtamae Alkawayti. (Rsalat Dukturah Ghyr Manshurata), Jamieat Alqahirata, Alqahr.

Alhilat, Mustafaa Qasim. (2015). Miqyas Hirman Li'anmat Altafkiru. Al'urdunu: Markaz Dibunu Litaelim Altafkir.

\section{REFERENCE LIST:}

Aljojo, N. (2017). Differences In Styles Of Thinking 'In Light Of Sternberg's Theory': A Case Study Of Different Educational Levels In Saudi Arabia. Journal of Technology and Science Education, 7(3), 333-346.

Bada, S. O. (2015). Constructivism Learning Theory: A Paradigm For Teaching And Learning. Journal Of Research \& Method In Education, 5(6), 66-70.

Bawaneh, A. K. A., Abdullah, A. G. K., Saleh, S., \& Yin, K. Y. (2011). Jordanian Students'thinking Styles Based On Herrmann Whole Brain Model. International Journal of Humanities and social science, 1(9), 89-97

Belousova, A., \& Pishchik, V. (2015). Technique Of Thinking Style Evaluating. (IJCRSEE) International 
Journal of Cognitive Research in Science, Engineering and Education, 3(2), 1-8.

Boer, A-L., \& Bothma, T., J. (2003). Thinking styles and their role in teaching and learning. IATUL Proceedings (New Series), Middle Eastern Technical University, Ankara, Turkey.

Bridewell, W. \& Bello, P. F. (2016). A Theory Of Attention For Cognitive Systems. Advances In Cognitive Systems, (4), 1-16.

Cao, M., Li, C. Y., Csete, J., \& Pan, Z. (2018). Usability Study of CAD for Clothing Thermal Computational Design Education. In Z. Pan, A. D. Cheok, \& W. Muller (Eds.), Transactions on Edutainment XIV, (pp. 232-244). Cham: Springer.

Doolittle, P. E. (2014). Complex Constructivism: A Theoretical Model Of Complexity And Cognition. International Journal Of Teaching And Learning In Higher Education, 26(3), 485-498.

Hughes, M., Hughes, P. \& Hodgkinson, I. R. (2017). In Pursuit Of A 'Whole-Brain' Approach To Undergraduate Teaching: Implications Of The Herrmann Brain Dominance Model. Studies In Higher Education., 42 (12), 2389-2405

Keat, T. S., Kumar, V., Rushdi, M. S. B., Nazri, N. A. B., \& Xuan, L. Z. X. L. Z. (2016). The relationship between brain dominance and academic performance: A cross-sectional study. Journal of Advances in Medicine and Medical Research, 1-9.

Nandhini, M. (2017). A Study On Brain Dominance And Academic Achievement Of Higher Secondary School Students In Chennai District. Review Of Research, 7(1), 1-10.

Nangaiyarkarasi, S., \& Kamatchi, S. (2014). Brain Dominance And Academic Achievement Of Eleventh Standard Students. Indian Journal Of Information Science And Services, 8(2), 59-62.

Oflaz, M. (2011). The Effect Of Right And Left Brain Dominance In Language Learning. $3^{\text {th }}$ World Conference On Educational Sciences (Wces), 3-7, February, Istanbul - Turkey.

Özgena, K., Tataroglu, B. \& Alkan, H. (2011). An Examination Of Brain Dominance And Learning Styles Of Pre-Service Mathematics Teachers. World Conference On Educational Sciences (Wces), 0307 February, Istanbul - Turkey.

Sharma, P., \& Neetu. (2011). A Study Of Learning-Thinking Style Of Secondary School Students In Relation To Their Academic Achievement. International Journal on New Trends in Education and Their Implications, 2(4), 115-123.

Singh, M. P., \& Gera, M. (2018). Effect Of Duval's Semiotic Approach On Higher Order Thinking Skill In Relation To Brain Dominance. Ijrar - International Journal Of Research And Analytical Review, 5(3), 869-873. 